\title{
Interactions between $N$-Ethylmaleimide-Sensitive Factor and GluR2 in the Nucleus Accumbens Contribute to the Expression of Locomotor Sensitization to Cocaine
}

\author{
Hai-Feng Lu, ${ }^{1 \star}$ Peng-Fei Wu, ${ }^{1,2,3 *}$ Yuan-Jian Yang, ${ }^{1 \star}$ Wen Xiao, ${ }^{1}$ Jun Fan, ${ }^{1}$ Jing Liu, ${ }^{1}$ Yuan-Long Li, ${ }^{1}$ Yi Luo, ${ }^{1}$ \\ Zhuang-Li Hu, ${ }^{1,2,3}$ You Jin,, ${ }^{1,2,3}$ Fang Wang, ${ }^{1,2,3}$ and Jian-Guo Chen ${ }^{1,2,3}$ \\ ${ }^{1}$ Department of Pharmacology, Tongji Medical College, Huazhong University of Science and Technology, Wuhan, Hubei 430030, China, ${ }^{2}$ Key Laboratory of \\ Neurological Diseases (HUST), Ministry of Education of China, Wuhan, Hubei 430030, China, and ${ }^{3}$ The Key Laboratory for Drug Target Researches and \\ Pharmacodynamic Evaluation of Hubei Province, Wuhan, Hubei 430030, China
}

\begin{abstract}
Many studies have reported a withdrawal-dependent increase in synaptic AMPA receptor (AMPAR) levels in the nucleus accumbens (NAc) of cocaine-sensitized rats; however, the exact relationship between the expression of sensitization and altered AMPAR surface expression in the NAc has not yet been investigated. We demonstrated that the expression of behavioral sensitization was negatively controlled by $\mathrm{N}$-ethylmaleimide-sensitive factor (NSF)-GluR2 interactions in the NAc. The upregulation of NSF-GluR2 interactions, which may be resulted by the increase in NSF S-nitrosylation after withdrawal from cocaine, was associated with the changes in the expression of behavioral sensitization. Disruption of NSF-GluR2 interactions in the NAc with a specific peptide, TAT-pep-R845A, increased the locomotor response of rats to cocaine by decreasing GluR2 surface insertion. In contrast, prevention of GluR2-containing AMPARs removal from synapses with Pep2-EVKI attenuated the expression of behavioral sensitization. Similarly, treatment with the nitric oxide donor, S-Nitroso- $N$-acetyl-DL-penicillamine (SNAP), attenuated the expression of locomotor sensitization by promoting GluR2 surface expression. This effect was mediated by the binding of S-nitrosylated NSF to GluR2, which promoted the surface expression of AMPARs. Noticeably, exogenous injection of SNAP into NAc also attenuated the expression of cocaine-induced conditioned place preference. Thus, these results indicate that increased NSF-GluR2 interactions in the NAc after withdrawal from cocaine attenuated the expression of behavioral sensitization and serves as a negative regulatory mechanism in drug-exposed individuals.
\end{abstract}

\section{Introduction}

The nucleus accumbens (NAc) occupies a key position in the neuronal circuitry of motivation and reward, including drug addiction (Kelley, 2004). Strong evidence has accumulated to support a requirement for glutamate transmission in the development of behavioral sensitization (Wolf, 1998). An increasing amount of literature indicates that repeated contingent or noncontingent exposure to cocaine followed by an abstinence period increases synaptic AMPAR levels in the NAc (Schmidt and Pierce, 2010; Wolf and Ferrario, 2010; Wolf and Tseng, 2012). However, subsequent studies indicate that the nature of increased synaptic AMPARs in behavioral sensitization is more complex than it

Received June 17, 2013; revised Dec. 13, 2013; accepted Dec. 20, 2013.

Author contributions: H.-F.L., P.-F.W., Y.-J.Y., F.W., and J.-G.C. designed research; H.-F.L., P.-F.W., Y.-J.Y., W.X., J.F., J.L., Y.-L.L., Y.L., and Y.J. performed research; H.-F.L., P.-F.W., Y.-J.Y., Z.-L.H., F.W., and J.-G.C. analyzed data; H.-F.L., P.-F.W., Y.-J.Y., F.W., and J.-G.C. wrote the paper.

This work was supported by grants from the National Basic Research Program of China (973 Program, No.2013CB531303), the National Natural Science Foundation of China (NSFC, No.81171258), the International Science and Technology Cooperation Program of China No.2011DFA32670 (J.G.C.), and by NSFC Grants No. 81222048 (F.W.).

*H.-F.L., P.-F.W., and Y.-J.Y. contributed equally to this work.

Correspondence should be addressed to either Dr Jian-Guo Chen or Dr Fang Wang, Department of Pharmacology, Tongji Medical College, Huazhong University of Science and Technology, 13 Hangkong Road, Wuhan 430030, China, E-mail: chenj@mails.tjmu.edu.cn or wangfangtj0322@163.com.

DOI:10.1523/JNEUROSCI.2594-13.2014

Copyright $\odot 2014$ the authors $\quad 0270-6474 / 14 / 343493-16 \$ 15.00 / 0$ seems (Boudreau and Wolf, 2005; Bachtell and Self, 2008; Ferrario et al., 2010; Wolf and Ferrario, 2010; Kourrich et al., 2012). At 1-3 weeks of withdrawal, GluR1/2-containing AMPARs are the major population that exhibits increased surface expression in the NAc of cocaine-sensitized rats (Ferrario et al., 2010). However, increased surface GluR1/2-containing AMPARs are no longer detected on withdrawal $41 \mathrm{~d}$ (WD 41) after noncontingent cocaine injections, whereas locomotor sensitization is still detected (McCutcheon et al., 2011). Moreover, GluR2-lacking AMPARs are added to NAc synapses after prolonged withdrawal (30-47 d) from cocaine self-administration (Conrad et al., 2008; Mameli et al., 2009; Ferrario et al., 2011). Calcium-permeable GluR2-lacking AMPARs have larger single channel conductance, and behavioral sensitization may be accompanied by a small increase in NAc levels of GluR2-lacking AMPARs (Boudreau et al., 2007). These findings raise the question of the exact significance of increased GluR1/2-containing AMPARs observed on the early withdrawal period.

What mechanisms underlie the upregulation of GluR1/2containing AMPARs after withdrawal from a sensitizing regimen of cocaine? Positive correlations have been found between the surface expression of GluR1 and mitogen-activated protein kinase signaling in the NAc of sensitized rats (Boudreau et al., 2007; Boudreau et al., 2009; Schumann and Yaka, 2009). A new study indicates that the elevated S-nitrosylation of stargazin contrib- 
utes to the upregulation of AMPARs during cocaine sensitization in the NAc shell (Selvakumar et al., 2013). The replacement of synaptic AMPARs by GluR2/3 subunits requires the interaction of GluR2 with $\mathrm{N}$-ethylmaleimide-sensitive factor (NSF) (Shi et al., 2001). NSF-GluR2 interactions are shown to be important to maintain AMPA-mediated transmission at the synapses (Nishimune et al., 1998; Song et al., 1998; Lüthi et al., 1999; Lee et al., 2002). Thus, withdrawal from repeated cocaine exposure may enable NSF to bind to GluR2 and promote the surface expression of GluR2. NSF is physiologically S-nitrosylated by endogenous nitric oxide (NO), and S-nitrosylated NSF mediates the surface expression of AMPARs (Huang et al., 2005). Interestingly, previous studies have indicated that endogenous NO signal is implicated in cocaine behavioral effects (Karatinos et al., 1995; Kim and Park, 1995). Thus, a NO-NSF-GluR2 mechanism may underlie the cocaine-induced synaptic adaptations. However, until now, there are few reports about the role of NSF-GluR2 interactions in locomotor sensitization.

In this study, we found that repeated cocaine injections augmented NSF-GluR2 interactions in the NAc neurons. Moreover, disrupted or further increased accumbal NSF-GluR2 interactions enhanced or attenuated the expression of behavior sensitization, respectively.

\section{Materials and Methods}

\section{Animals}

Male Sprague-Dawley rats aged 3-4 months weighing 250-300 g were used in the present study. The rats were housed individually on a controlled $12 \mathrm{~h}$ light cycle at a constant temperature $\left(22 \pm 2^{\circ} \mathrm{C}\right)$ and humidity of $50 \pm 10 \%$ with food and water provided ad libitum at all times unless specified. The research was conducted in accordance with the Declaration of Helsinki and with the Guide for Care and Use of Laboratory Animals as adopted and promulgated by the United National Institutes of Health. All experimental protocols were approved by the Review Committee for the Use of Human or Animal Subjects of Huazhong University of Science and Technology.

\section{Agents}

SNAP and $\mathrm{NaNO}_{2}$ were purchased from Sigma-Aldrich. Cocaine hydrochloride ( purity $>98 \%$ ) was obtained from Qinghai Pharmaceutical Factory. TAT-pep-R845A peptide (Biotin-YGRKKRRQRRR KAMKVAKNPQ), TAT control peptide (Biotin-YGRKKRRQRRR), Pep2-EVKI peptide (Biotin-YGRKKRRQRRRNVYGIEEVKI), and Pep2-SVKE peptide (Biotin-YGRKKRRQRRRNVYGIESVKE) were purchased from a commercial supplier (Jier). SNAP (1-2 $\mu \mathrm{g} / \mu \mathrm{l}), \mathrm{NaNO}_{2}$ $(10 \mu \mathrm{g} / \mu \mathrm{l})$, and peptides $(50 \mu \mathrm{g} / \mu \mathrm{l})$ were dissolved with artificial CSF (aCSF) before use with aCSF as the vehicle in behavior test. The concentrations of SNAP and peptides in bath solution are $100 \mu \mathrm{m}$ in aCSF.

\section{Surgery and intracranial injections}

Briefly, rats were anesthetized with chloral hydrate $(40 \mathrm{mg} / \mathrm{kg})$ before surgery, and then placed in a stereotaxic apparatus. Two 22 gauge cannulas (stainless steel) were bilaterally implanted to the NAc (coordinates are in reference to bregma: $\mathrm{AP},+1.8 \mathrm{~mm}$; $\mathrm{ML}, \pm 1.6 \mathrm{~mm}$; DV, -5.8 $\mathrm{mm})$. The rats were allowed 5-7 $\mathrm{d}$ for recovery before behavioral testing began. On the day of the experiment, the injection cannula was connected via PE20 tubing to a $10 \mu \mathrm{l}$ microsyringe, driven by a microinjection pump. Drugs were infused into the NAc in freely moving rats and solution was injected at a rate of $0.5 \mu \mathrm{l} / \mathrm{min}$ with volume of $0.5 \mu \mathrm{l}$ per side. Following injection, the injection cannula was left for an additional $1.5 \mathrm{~min}$ before withdrawal to minimize dragging of injected liquid along the injection track.

\section{Behavioral measurements}

Motor activity (distance traveled, $\mathrm{cm}$ ) was recorded for $1 \mathrm{~h}$ in locomotion cages $(45 \times 45 \mathrm{~cm})$ immediately after each systemic injection by using AniLab Software (Ningbo). Rats were given intraperitoneal (i.p.) injec- tion of saline ( $1 \mathrm{ml} / \mathrm{kg}$ of body weight) or cocaine $(15 \mathrm{mg} / \mathrm{kg})$ once daily for seven consecutive days. At day 14 after the last injection, behavioral responses to a challenging dose of cocaine $(10 \mathrm{mg} / \mathrm{kg}$, i.p.) were analyzed for $1 \mathrm{~h}$ and information about horizontal activities was recorded at $5 \mathrm{~min}$ intervals. In the test day, rats were placed on the test environment for $1 \mathrm{~h}$ habituation.

Cocaine place-conditioning (CPP) were conducted in a Plexiglas apparatus $(46 \times 24 \times 22 \mathrm{~cm})$ with a sound-attenuating lid and a removable center divider separating two compartments of equal size. Each side of the apparatus differed in wall pattern and floor texture. On conditioning sessions ( $45 \mathrm{~min}$ ), the two compartments were separated by solid divider, confining the animal to one compartment. On test session (15 min), animals had free access to both compartments through a divider with a door. Both dividers were opaque and colored on each side to match the compartment-facing wall pattern, marble or wood, respectively. Conditioning began with a preconditioning session for $15 \mathrm{~min}$ (pretest), in which experimentally naive animals had free-access to both compartments to establish initial compartment bias. This was followed by once daily conditioning sessions for $8 \mathrm{~d}$, alternating pairings of distinct compartments with either $15 \mathrm{mg} / \mathrm{kg}$ cocaine or saline. The CPP score was defined as the time (in seconds) spent in the cocaine-paired chamber minus the time spent in the saline-paired chamber during CPP testing.

Sucrose preference test (SPT) was performed as follows. Cannulas were bilaterally implanted to the NAc as described above. After a $7 \mathrm{~d}$ recovery period, rats were exposed to a palatable sucrose solution (1\%; $\mathrm{m} / \mathrm{v}$ ) for $48 \mathrm{~h}$ to habit sucrose intake. After $6 \mathrm{~h}$ of water deprivation on the third day, rats were exposed to two identical bottles, one was filled with sucrose solution, and the other with water, for $1 \mathrm{~h}$. Sucrose and water consumption was determined by measuring the change in the volume of fluid consumed. Sucrose preference was defined as the ratio of the volume of sucrose versus total volume of sucrose and water consumed during the $1 \mathrm{~h}$ test.

Conditioned taste aversion (CTA) was performed according to previous reports (Ma et al., 2011). In brief, rats were deprived of water for $24 \mathrm{~h}$ and then given two pipettes that were filled with water for $10 \mathrm{~min}$ once a day. They were trained $3 \mathrm{~d}$ to get their daily water ration. On conditioning day, the rats were presented with two pipettes filled with saccharin for 10 min. Forty minutes later, they were injected with $0.05 \mathrm{M} \mathrm{LiCl}(2 \%$ body weight) intraperitoneally. On the next $2 \mathrm{~d}$, rats were presented daily for 10 min with two pipettes filled with water. On the third day after conditioning, the rats were presented with a random array of six pipettes, three filled with saccharin and three filled with water for $10 \mathrm{~min}$. The rats explored to consume or avoid the contents of the pipettes, and their liquid consumption was recorded to test CTA. For the high CTA conditioning, all rats were trained as above, except that on the conditioning day, rats received intraperitoneal injection of $0.15 \mathrm{M} \mathrm{LiCl}$ instead of 0.05 $\mathrm{M} \mathrm{LiCl}$. The results were quantified by an aversion index (AI), defined as $\mathrm{AI}=[($ milliliters of water $) /($ milliliters of water + milliliters of saccharin) $] \times 100 \%$ consumed in the test.

\section{Peptides localization in brain}

Rats were anesthetized 60 min following microinjection with peptides and perfused intracardially with PBS followed by $4 \%$ paraformaldehyde in PBS. After perfusion, rats were decapitated and the brains were removed and placed for postfixation in $30 \%$ sucrose in PBS for $48 \mathrm{~h}$ at $4^{\circ} \mathrm{C}$. Brains were frozen and sliced at thickness of $20 \mu \mathrm{m}$ with a microtome (Leica, RM2245). Then, slices were incubated with PBS for $1 \mathrm{~h}$, followed by $1 \mathrm{~h}$ incubation with streptavidin-Alexa Fluor 568 (1:2000; S-11226, Invitrogen) in PBS at room temperature to detect the biotin-labeled peptide. Slices were then washed thrice with PBS and the third wash contained Hoechst dye (1:5000, No. 33258, Invitrogen) in PBS for nucleus staining. Slices were loaded on slides and examined using a laser confocal microscope (LSM510 Carl Zeiss).

\section{Immunostaining}

Rats were anesthetized and perfused intracardially with PBS followed by $4 \%$ paraformaldehyde in PBS. After perfusion, rats were decapitated and the brains removed and placed for postfixation in 30\% sucrose in PBS for $48 \mathrm{~h}$ at $4^{\circ} \mathrm{C}$. Brain sections $(20 \mu \mathrm{m})$ that washed in blocking medium 
A

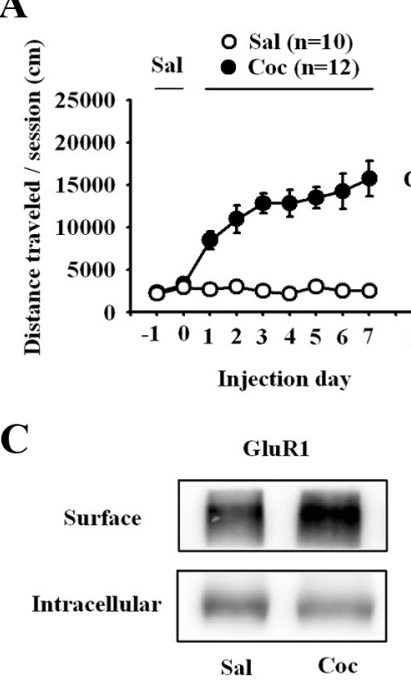

D

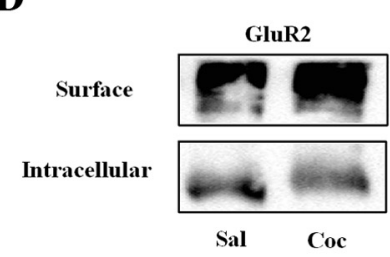

E
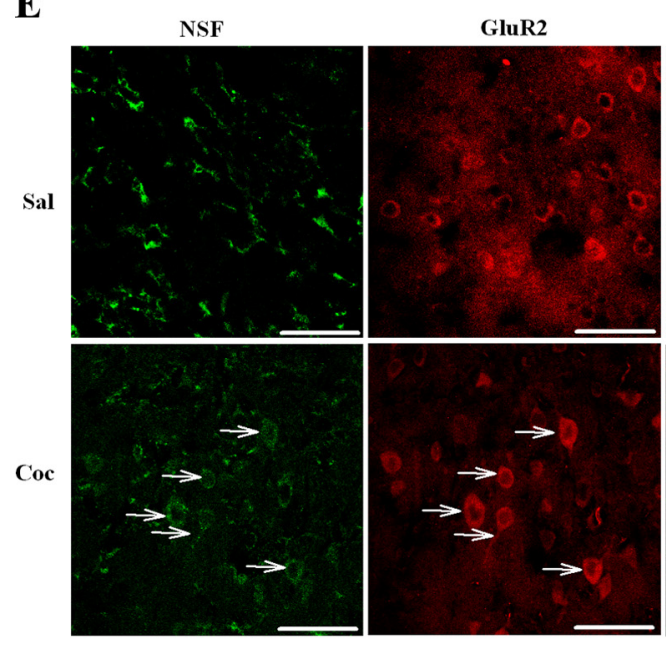

F

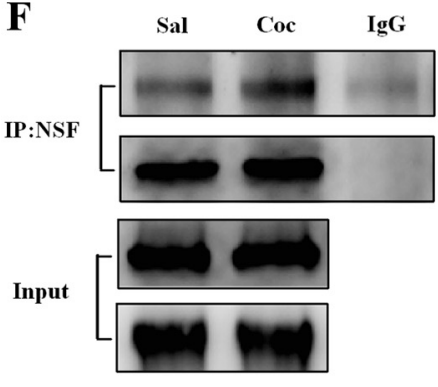

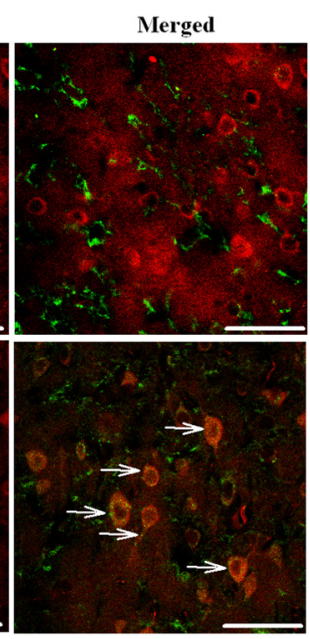

B
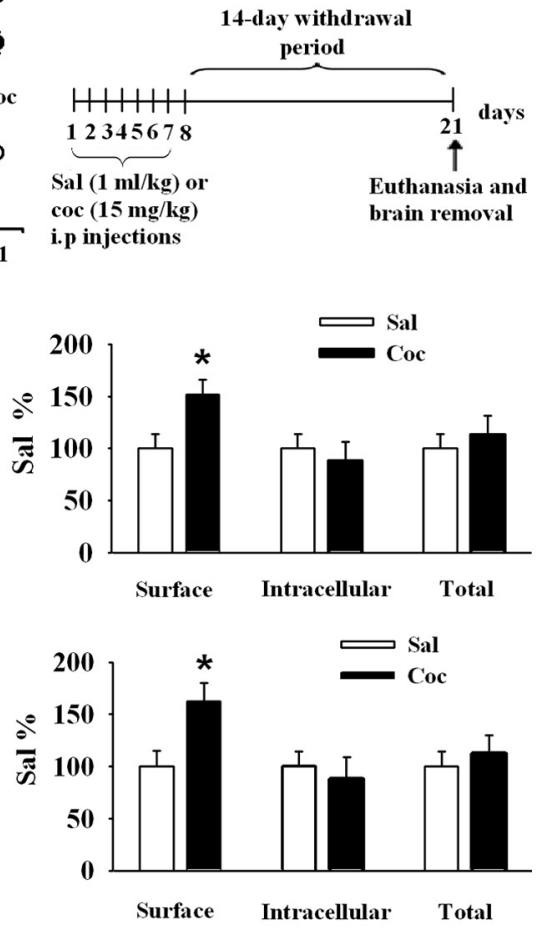

GluR2
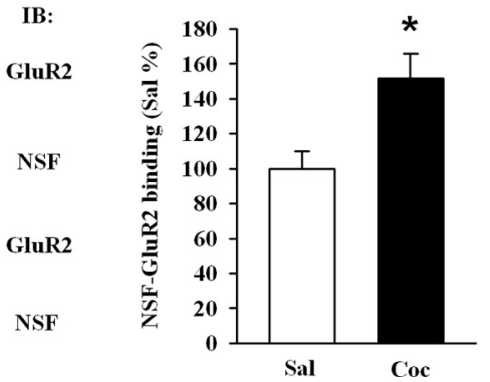

Figure 1. Repeated cocaine injections increase surface expression of GluR1/2 and interactions between NSF and GluR2 in the NAc after $14 \mathrm{~d}$ withdrawal. $\boldsymbol{A}$, Regimen of behavioral sensitization: the immediate locomotor response to a fixed dose of cocaine (15 $\mathrm{mg} / \mathrm{kg}$ ) increased across days of testing, and a challenge dose of cocaine $(10 \mathrm{mg} / \mathrm{kg}$ ) at day 14 of withdrawal induced a robust locomotor response (Sal: saline; Coc: cocaine, ${ }^{*} p<0.05$ vs saline). $\boldsymbol{B}$, Timeline of the experimental procedure. $\boldsymbol{C}, \boldsymbol{D}$, Cell surface, intracellular, and total levels of GluR1 and GluR2 in the NAc. Withdrawal from cocaine increased both surface expression of GluR1 and GluR2. Data from the cocaine group were normalized to the mean of the saline group. ( $n=5-8$ rats for saline and cocaine group respectively; ${ }^{*} p<0.05$ vs saline). $\boldsymbol{E}$, Staining of NAc slices for NSF (left) and GluR2 (middle) in saline (top),

containing $0.1 \%$ Triton $\mathrm{X}-100$ and 5\% BSA, and incubated overnight $\left(4^{\circ} \mathrm{C}\right)$ with primary antibodies against GluR2 (1:500 dilution; Millipore) and NSF (1:1000 dilution; CST) followed by Alexa dye-tagged secondary antibodies. Slices were loaded on slides and examined using a laser confocal microscope (LSM510, Carl Zeiss).

\section{Coimmunoprecipitation}

After drug treatments, NAc slices were chilled on ice and briefly washed with ice-cold ACSF. Protein extracts were prepared by homogenization in buffer (50 mm Tris-base $\mathrm{pH} 7.4,100$ $\mathrm{mm} \mathrm{NaCl}, 1 \% \mathrm{NP}-40,10 \mathrm{~mm}$ EDTA, $20 \mathrm{~mm}$ $\mathrm{NaF}, 1 \mathrm{~mm}$ PMSF, $\left.3 \mathrm{~mm} \mathrm{Na} \mathrm{VO}_{4}\right)$. Supernatants $(500 \mu \mathrm{g})$ were then incubated with $10 \mu \mathrm{g}$ of NSF antibody overnight at $4^{\circ} \mathrm{C}$ with constant shaking. The antibody-bound complexes were incubated with Protein A/G PLUSAgarose (Santa Cruz Biotechnology) for $2 \mathrm{~h}$ at $4^{\circ} \mathrm{C}$. The protein-bound beads were washed in buffer and pelleted by centrifugation for $3 \mathrm{~min}$ at $3000 \times g$. The beads were resuspended in SDS sample buffer, and the immune complexes were eluted by boiling. The eluted proteins were subjected to electrophoresis and immunoblotted with anti-GluR2 (1:500 dilution; Millipore) or anti-NSF (1:1000 dilution; CST).

\section{Surface receptor cross-linking with $B S^{3}$}

Protein crosslinking was performed according to previous reports (Boudreau and Wolf, 2005; Mao et al., 2009). The rats were decapitated and their brains were rapidly removed to cut into coronal sections $(400 \mu \mathrm{m})$. Slices were incubated in a holding chamber for $1 \mathrm{~h}$ in oxygenated ACSF at $30^{\circ} \mathrm{C}$. The NAc slices were dissected and added to Eppendorf tubes containing ice-cold aCSF, which was spiked with 2 $\mathrm{mm}$ bis (sulfosuccinymidal) suberate $\left(\mathrm{BS}^{3}\right.$; Pierce Biotechnology) immediately after addition of the tissue. The dissected pieces of tissue contained both core and shell subregions of the NAc. Then, the tissue was cross-linked for 60 min at $4^{\circ} \mathrm{C}$ with gentle agitation and this reaction was terminated by quenching with $100 \mathrm{~mm}$ glycine $\left(15 \mathrm{~min}\right.$ at $\left.4^{\circ} \mathrm{C}\right)$. The tissue was pelleted by brief centrifugation, resuspended in icecold lysis buffer containing protease and phosphatase inhibitors, homogenized rapidly by sonicating for $5 \mathrm{~s}$, and centrifuged $(12000 \times g$ for $15 \mathrm{~min}$ at $4^{\circ} \mathrm{C}$ ). The supernatant fraction was aliquoted and stored at $-80^{\circ} \mathrm{C}$ before using for Western blot. The values (diffuse den-

$\leftarrow$

and cocaine-exposed (bottom) rats. Merged images (right) showed increased colocalization of GluR2 (red) and NSF (green) after withdrawal from cocaine (white arrows). Scale bars, $50 \mu \mathrm{m}$. $\boldsymbol{F}$, The NAc from saline and cocaine-exposed rats were dissected on WD 14. Protein homogenates were immunoprecipitated with anti-NSF, and immunocomplex and homogenates (input) were immunoblotted for NSF and GluR2. Data were first expressed as the ratio of the protein in the immunocomplex (Co-IP) to total lysate. Then, data from the cocaine group were normalized to the mean of the saline group. ( $n=4$ per group, ${ }^{*} p<0.05$ vs saline). All data are mean \pm SEM. 
A

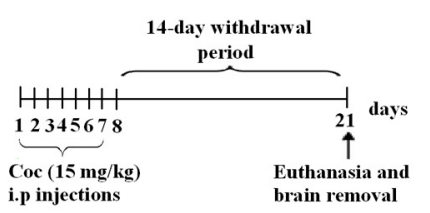

B

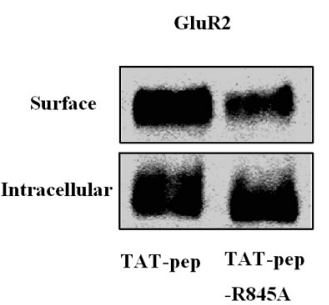

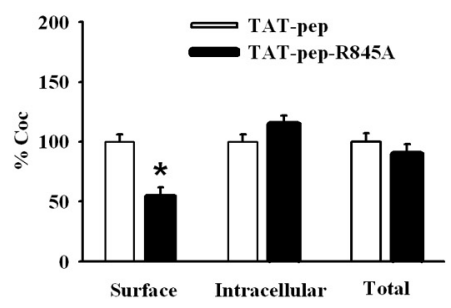

C

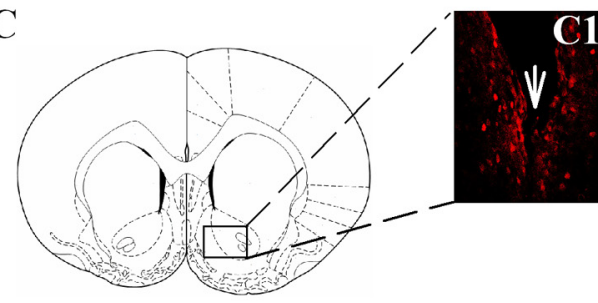

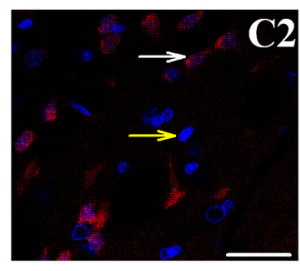

TAT-pep

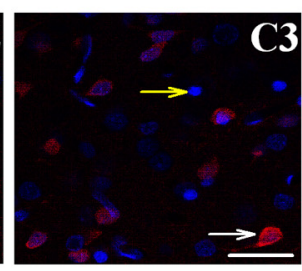

TAT-pep-R845A
D

Timeline

$\mathbf{E}$
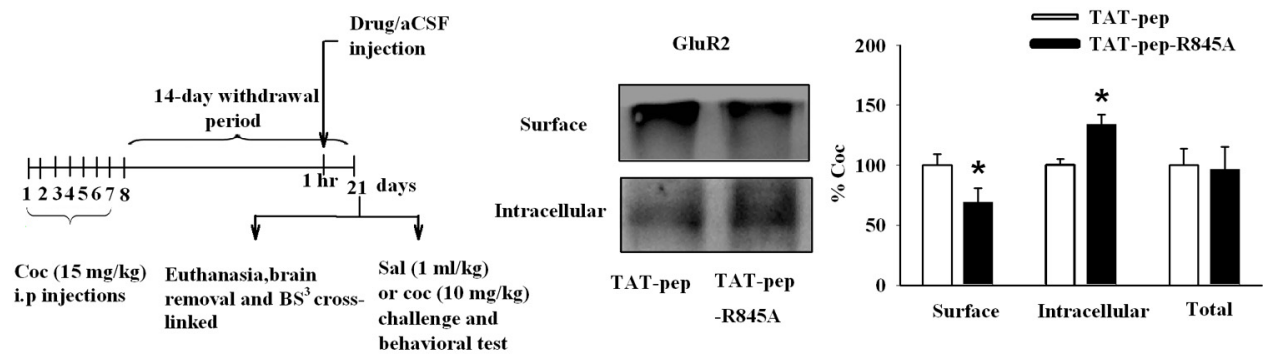

F

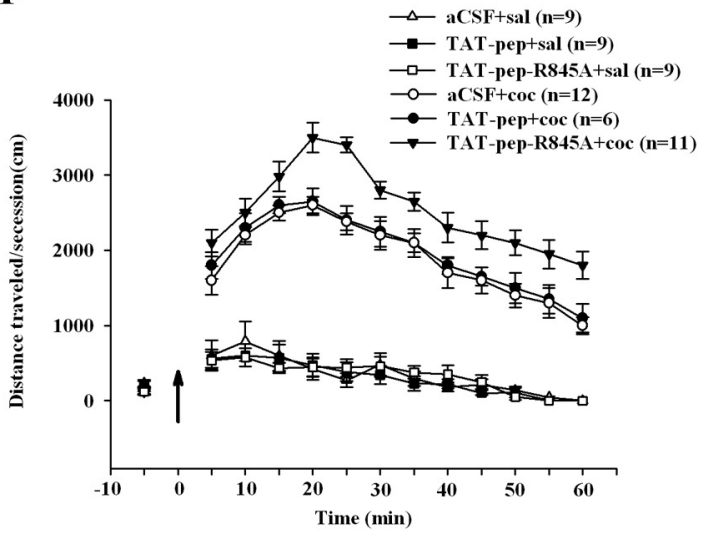

H

Timeline

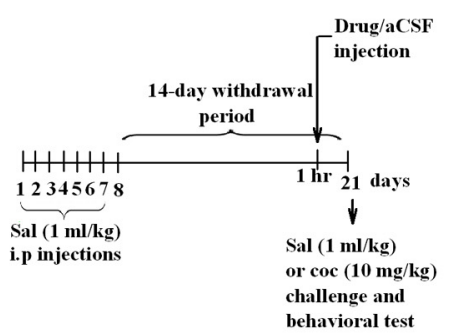

I
G

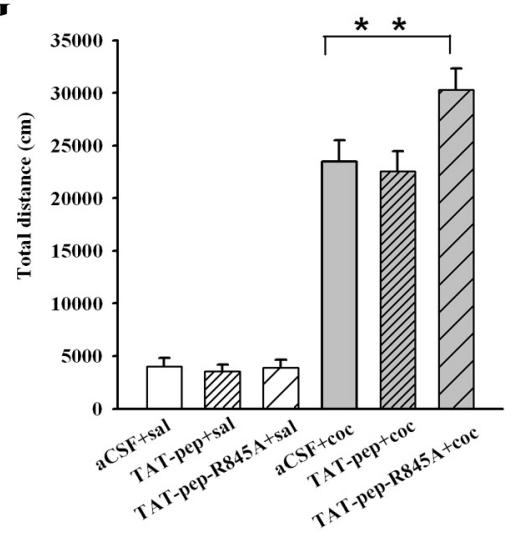

aCSF + sal $(n=11)$

$\rightarrow$ TAT-pep-R845A+sal (n=11) $\neg-\operatorname{aCSF}+\operatorname{coc}(n=10)$ $\rightarrow$ TAT-pep+coc $(\mathbf{n}=9)$

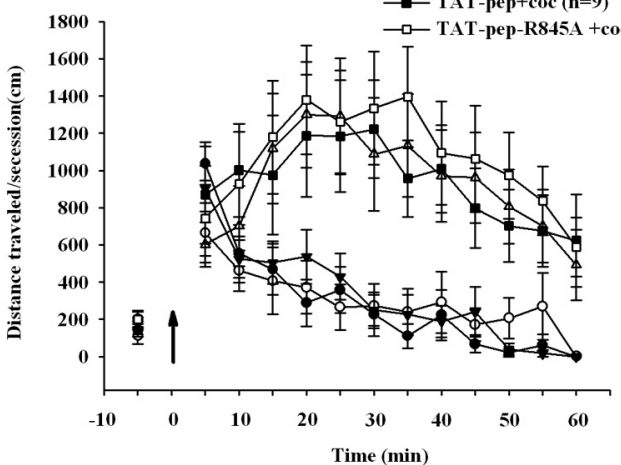


sities) for surface, intracellular, and total (surface + intracellular) protein levels were normalized to a loading control ( $\beta$-actin; 1:500 dilution; Santa Cruz Biotechnology).

\section{S-nitrosylation assay (biotin switch assay)}

Detection of S-nitrosylated NSF was according to the method in previous study (Jaffrey et al., 2001, 2002). The rats were decapitated and their brains were rapidly removed to cut into coronal sections $(400 \mu \mathrm{m})$. The NAc region was dissected and homogenized in $1 \mathrm{ml} \mathrm{HEN} \mathrm{buffer}(250 \mathrm{~mm}$ HEPES pH 7.7, 0.1 mм EDTA, 0.1 mm neocuproine) with $1 \%$ NP40 (Nonidet P-40), protease inhibitor mixture and $1 \mathrm{~mm}$ PMSF, sonicated and then centrifuged at $12,000 \mathrm{~g}$ for $15 \mathrm{~min}$ at $4^{\circ} \mathrm{C}$. The protein pellet was resuspended in blocking buffer (HEN buffer with 2.5\% SDS and $20 \mathrm{~mm}$ methylmethanethiosulfonate; MMTS) to a final concentration. The free thiols were blocked by MMTS at $50^{\circ} \mathrm{C}$ for $20 \mathrm{~min}$. The excess MMTS was removed by ice-cold acetone precipitation for 20 min followed by centrifugation at $2000 \mathrm{~g}$ for $10 \mathrm{~min}$. This precipitation was repeated several times to remove the residual MMTS. After removal of the acetone, the proteins were resuspended in HENS buffer. Then, the suspension was added biotin HPDP prepared fresh as a $4 \mathrm{~mm}$ stock in dimethylsulfoxide from a $50 \mathrm{~mm}$ stock suspension in dimethylformamide. Sodium ascorbate was added to a final concentration of $1 \mathrm{~mm}$. After incubation for $2 \mathrm{~h}$ at $25^{\circ} \mathrm{C}$, biotinylated proteins were precipitated by streptavidin-agarose beads. The streptavidin-agarose was then pelleted and washed five times with HENS buffer. The biotinylated proteins were eluted by SDS/PAGE sample buffer and S-nitrosylated NSF were detected by Western blot using anti-NSF antibody (1:500 dilution; CST).

\section{Western blot analysis}

Protein samples $(40 \mu \mathrm{g})$ were separated by $8 \%$ SDS-PAGE and then transferred to nitrocellulose membranes (transfer buffer: $25 \mathrm{~mm}$ Tris, 190 mu glycine, $20 \%$ methanol, $0.5 \%$ SDS). The membranes were washed in Tris-buffered saline (TBS; $20 \mathrm{~mm}$ Tris- $\mathrm{HCl} \mathrm{pH}$ 7.6, $140 \mathrm{~mm} \mathrm{NaCl}$ ) and blocked with 5\% BSA in TBS containing 0.5\% Tween 20 (TBS-T). Then membranes were incubated overnight at $4^{\circ} \mathrm{C}$ with the following primary antibodies: GluR1 (1:500 dilution; Millipore), GluR2 (1:500 dilution; Millipore), nNOS (1:2000 dilution; Millipore). Membranes were washed with TBS-T solution, incubated for $60 \mathrm{~min}$ with horseradish peroxidase (HRP)-conjugated anti-rabbit IgG or anti-mouse IgG (1:5000 dilution; Millipore), washed with TBS-T, rinsed with double-deionized water, and immersed in enhanced chemiluminescence-detecting substrate (Super Signal West Pico; Pierce Chemical). Images were captured with Micro Chemi (DNR Bio-Imaging Systems) or visualized with $\mathrm{x}$-ray films (Kodak X-Omat). The pictures or films were scanned and the optical density of the bands was determined using NIH ImageJ software.

$\leftarrow$

Figure 2. Disruption of NSF-GluR2 interaction inhibits the transport of GluR2-containing AMPARs to the cell surface in the NAc and increases the expression of behavioral sensitization to cocaine. $\boldsymbol{A}, \boldsymbol{D}, \boldsymbol{H}$, Timelines of the experimental procedure. $\boldsymbol{B}$, Disruption of NSF-GluR2 interactions by specific peptide TAT-pep-R845A (100 $\mu \mathrm{m}, 30 \mathrm{~min})$ inhibited the surface expression of GluR2 in ex vivo slices. Data from the TAT-pep-R845A group were normalized to the mean of the TAT-pep group. ( $n=5$ rats for each group; ${ }^{* *} p<0.01$, different from control peptide). $C$, Microinjection of TAT-pep or TAT-pep-R845A peptides led to internalization of peptides into NAccells. The big white arrow shows the site of injection (C1). Biotin-labeled TAT-pep ( $(2 ; n=$ 4), or TAT-pep-R845A (C3;n=5) were microinjected into the NAc $(50 \mu \mathrm{g} / \mu \mathrm{l}, 0.5 \mu \mathrm{l}$ per side). Transcellular translocation was detected by streptavidin conjugated to AlexaFluor 568 (red) and to nuclear Hoechst (blue) staining. Small white arrows indicate the positive cells (red staining and blue nuclei) and small yellow arrows indicate negative cells (blue nuclei only). $\boldsymbol{E}$, Disruption of NSF-GluR2 interactions by specific peptide TAT-pep-R845A intracranial injections inhibited the surface expression of GluR2. Data from the TAT-pep-R845A group were normalized to the mean of the TAT-pep group. ( $n=5-8$ rats for each group; ${ }^{* *} p<0.01$, different from control peptide). $\boldsymbol{F}$, Pretreatment with TAT-pep-R845A for 60 min increased responses to the challenge dose (black arrow) of cocaine. $\mathbf{G}$, The bar diagram shows total travel distance in each group $(n=$ $6-12$ rats for each group; ${ }^{*} p<0.05$, different from the other experimental groups). $I$, Pretreatment with TAT-pep-R845A for $60 \mathrm{~min}$ did not alter acute cocaine or saline-induced (black arrow) locomotor activity. All data are mean \pm SEM.

\section{NO assay}

NO production was assessed by measuring the amount of nitrite, a stable metabolic product of NO (Baratta et al., 2002). In brief, NAc tissue was lysed $(10 \mu \mathrm{l} / \mathrm{mg})$ in Griess lysis buffer (50 mM Tris- $\mathrm{HCl} \mathrm{pH} \mathrm{8.0,} 150 \mathrm{~mm}$ $\mathrm{NaCl}, 5 \mathrm{~mm} \mathrm{KCl}, 1 \% \mathrm{NP} 40,1 \mathrm{~mm}$ phenylmethylsulfonyl fluoride, $1 \mathrm{~mm}$ bathocuproinedisulfonic acid, $1 \mathrm{~mm}$ diethylenetriaminepenta-acetic acid, $10 \mathrm{~mm} N$-ethylmaleimide). Tissue lysate $(100 \mu \mathrm{l})$ was mixed with $100 \mu \mathrm{l}$ Griess reagent, which was prepared by mixing equal volumes of stock A ( $1 \%$ sulfanilamide and $5 \%$ phosphoric acid) and stock B $(0.1 \%$ $\mathrm{N}$-[naphthyl] ethylenediamine dihydrochloride). After $10 \mathrm{~min}$ incubation at room temperature, the absorbance was measured at $540 \mathrm{~nm}$ in a microplate reader.

\section{Slice preparation}

Briefly, under deep anesthesia, the brain was removed quickly after decapitation and 300- $\mu \mathrm{m}$-thick sagittal slices containing NAc were made with a Vibrate tissue slicer (VT 1000S; Leica) in ice-cold aCSF containing 119 sucrose, $3.5 \mathrm{~mm} \mathrm{KCl}, 1.3 \mathrm{~mm} \mathrm{MgSO}_{4}, 2.5 \mathrm{~mm} \mathrm{CaCl}_{2}, 1 \mathrm{~mm} \mathrm{NaH} \mathrm{PO}_{4}$, $26.2 \mathrm{~mm} \mathrm{NaHCO}_{3}$, and $11 \mathrm{~mm}$ glucose that was maintained at $\mathrm{pH} 7.4$ by carbogen $\left(95 \% \mathrm{O}_{2} / 5 \% \mathrm{CO}_{2}\right)$. $\mathrm{NaCl}$ was replaced by sucrose to improve the survival of neurons during slicing. Freshly cut slices were incubated in an incubating chamber for at least $1.5 \mathrm{~h}$ before using in oxygenated aCSF without sucrose but physiological concentration of $\mathrm{NaCl}(119 \mathrm{~mm})$. The solutions were saturated with $95 \% \mathrm{O}_{2} / 5 \% \mathrm{CO}_{2}$.

\section{Specific experiments}

Experiment 1: Effect of withdrawal from repeated cocaine exposure on surface expression of GluR1/2 and NSF-GluR2 interactions in NAc. We initially assessed the effect of withdrawal from repeated cocaine exposure on surface expression of GluR1/2 and NSF-GluR2 interactions in NAc. For this purpose, we used two groups of rats ( $n=13-17$ per group) in an experimental design that included the between-subjects factor of cocaine dose $(0$ and $15 \mathrm{mg} / \mathrm{kg})$; the dependent measures were surface expression of GluR1/2, NSF-GluR2 colocalization and NSF-GluR2 interaction levels. About half of the rats underwent saline injections $(0.9 \%, 1 \mathrm{ml} / \mathrm{kg})$, whereas the other rats received cocaine injections $(15 \mathrm{mg} / \mathrm{kg})$ once per day on seven consecutive days. On each pretreatment day, each rat was placed in locomotion cages $(45 \times 45 \mathrm{~cm})$. The NAc (core and shell) were removed for assay $14 \mathrm{~d}$ after the last pretreatment injection (WD14). In each experimental condition, approximately one-third of the rats $(n=$ 5-8 per group) were used for $\mathrm{BS}^{3}$ cross-linked, one-third ( $n=4-5$ per group) were used for immunostaining experiment and the other onethird ( $n=4$ per group) were used for coimmunoprecipitation.

Experiment 2: Effect of disruption of NAc NSF-GluR2 interactions on surface expression of GluR2 and cocaine-induced locomotor sensitization. We initially assessed the effect of specific NSF-GluR2 interaction blocking peptide (pep-R845A conjugated to TAT; Joels and Lamprecht, 2010) on the surface expression of GluR2 in NAc of cocaine-exposed rats. For this purpose, we used four groups of rats ( $n=5-8$ per group) in an experimental design that included the between-subjects factors of drug (TAT-pep, TAT-pep-R845A) and drug delivery mode (ex vivo slices, in vivo intracranial injection). The dependent measure was the GluR2 surface expression. All rats received cocaine injections $(15 \mathrm{mg} / \mathrm{kg}$ ) once per day on seven consecutive days and then withdrawal for $14 \mathrm{~d}$. On each pretreatment day, each rat was placed in locomotion cages $(45 \times 45 \mathrm{~cm})$. In ex vivo slices experimental condition, NAc slices from cocaineexposed rats were incubated with TAT-pep $(100 \mu \mathrm{M})$ or TAT-pep-R845A $(100 \mu \mathrm{M})$ for $30 \mathrm{~min}$ before $\mathrm{BS}^{3}$ cross-linked. In in vivo intracranial injection experimental condition, TAT-pep ( $25 \mu \mathrm{g}$ per side) or TATpep-R845A ( $25 \mu \mathrm{g}$ per side) was injected into NAc for $60 \mathrm{~min}$ before decapitate.

To determine the role of the increased binding of NSF to GluR2 in cocaine-induced locomotor sensitization, we used six groups of rats $(n=$ 6-12 per group) in an experimental design that included the betweensubjects factors of drug (aCSF, TAT-pep and TAT-pep-R845A) and cocaine challenge ( 0 and $10 \mathrm{mg} / \mathrm{kg}$ ). The dependent measure was travel distance. All rats received cocaine injections $(15 \mathrm{mg} / \mathrm{kg}$ ) once per day on seven consecutive days. On each pretreatment day, each rat was placed in locomotion cages $(45 \times 45 \mathrm{~cm})$. Fourteen days after the last pretreatment 
injection (WD14), we bilaterally injected with aCSF ( $0.5 \mu$ l per side), TAT-pep ( $25 \mu \mathrm{g}$ per side), or TAT-pep-R845A ( $25 \mu \mathrm{g}$ per side) into NAc and assessed cocaine $(0$ and $10 \mathrm{mg} / \mathrm{kg}$ ) induced locomotor sensitization 60 min later.

Experiment 3: Effect of TAT-pep-R845A on acute cocaine-induced locomotor activity. We further determined whether TAT-pep-R845Aaffected acute cocaine-induced locomotor activity. For this purpose, we used six groups of rats ( $n=9-11$ per group) in an experimental design that included the between-subjects factors of drug (aCSF, TAT-pep and TATpep-R845A) and acute cocaine $(0$ and $10 \mathrm{mg} / \mathrm{kg})$ administration. The dependent measure was travel distance. All rats were placed in locomotion cages $(45 \times 45 \mathrm{~cm})$ for $1 \mathrm{~h}$ habituation. The rats were bilaterally injected with aCSF $(0.5 \mu \mathrm{l}$ per side), TAT-pep ( $25 \mu \mathrm{g}$ per side), or TATpep-R845A (25 $\mu \mathrm{g}$ per side) into NAc and assessed acute cocaineinduced ( 0 and $10 \mathrm{mg} / \mathrm{kg}$ ) locomotor activity $60 \mathrm{~min}$ later.

Experiment 4: Effect of blocking PICK1-mediated GluR2 endocytosis in NAc on surface expression of GluR2 and locomotor sensitization. We initially assessed the effect of specific blocking peptide for protein interacting with $\mathrm{C}$ kinase 1 (PICK1)-GluR2 interaction on surface expression of GluR2 in NAc of cocaine-exposed rats. For this purpose, we used four groups of rats ( $n=5-7$ per group) in an experimental design that included the between-subjects factors of drug (Pep2-SVKE, Pep2-EVKI) and drug delivery mode (ex vivo slices, in vivo intracranial injection). The dependent measure was the surface expression of GluR2. All rats received cocaine injections $(15 \mathrm{mg} / \mathrm{kg})$ once per day on seven consecutive days and then withdrawal for $14 \mathrm{~d}$. On each pretreatment day, each rat was placed in locomotion cages $(45 \times 45 \mathrm{~cm})$. In ex vivo slices experimental condition, NAc slices from cocaine-exposed rats were incubated with Pep2-SVKE $(100 \mu \mathrm{M})$ or Pep2-EVKI $(100 \mu \mathrm{M})$ for $30 \mathrm{~min}$ before $\mathrm{BS}^{3}$ cross-linked. In in vivo intracranial injection experimental condition, Pep2-SVKE ( $25 \mu$ g per side) or Pep2-EVKI ( $25 \mu$ g per side) was injected into NAc for $60 \mathrm{~min}$ before decapitation.

To determine whether inhibition of PICK1-mediated GluR2 endocytosis in NAc affected cocaine-induced locomotor sensitization, we used six groups of rats ( $n=7-12$ per group) in an experimental design that included the between-subjects factors of drug (aCSF, Pep2-SVKE and Pep2-EVKI) and cocaine challenge ( 0 and $10 \mathrm{mg} / \mathrm{kg})$. The dependent measure was travel distance. All rats received cocaine injections $(15 \mathrm{mg} /$ $\mathrm{kg}$ ) once per day on seven consecutive days. On each pretreatment day, each rat was placed in locomotion cages $(45 \times 45 \mathrm{~cm})$. Fourteen days after the last pretreatment injection (WD14), the rats were bilaterally injected with aCSF $(0.5 \mu$ l per side), Pep2-SVKE (25 $\mu$ g per side) or Pep2-EVKI ( $25 \mu \mathrm{g}$ per side) into NAc and assessed cocaine-induced (0 and $10 \mathrm{mg} / \mathrm{kg}$ ) locomotor sensitization after $60 \mathrm{~min}$.

Experiment 5: Effect of Pep2-EVKI on acute cocaine-induced locomotor activity. We further determined whether Pep2-EVKIaffected acute cocaine-induced locomotor activity. For this purpose, we used six groups of rats ( $n=8-11$ per group) in an experimental design that included the between-subjects factors of drug (aCSF, Pep2-SVKE, and Pep2-EVKI) and acute cocaine $(0$ and $10 \mathrm{mg} / \mathrm{kg}$ ) administration. The dependent measure was travel distance. All rats were placed in locomotion cages $(45 \times$ $45 \mathrm{~cm}$ ) for $1 \mathrm{~h}$ habituation. The rats were bilaterally injected with aCSF (0.5 $\mu$ l per side), Pep2-SVKE ( $25 \mu$ g per side) or Pep2-EVKI ( $25 \mu$ g per side) into NAc and assessed acute cocaine-induced (0 and $10 \mathrm{mg} / \mathrm{kg}$ ) locomotor activity $60 \mathrm{~min}$ later.

Experiment 6: Effect of withdrawal from repeated cocaine exposure on $S$-nitrosylated NSF levels, nNOS levels, and NO content in NAc. How might cocaine treatment increase NSF-GluR2 interactions in the NAc? To determine the relationship between NSF-GluR2 interactions and S-nitrosylation of NSF, we used two groups of rats ( $n=15$ per group) in an experimental design that included the between-subjects factor of cocaine dose ( 0 and $15 \mathrm{mg} / \mathrm{kg}$ ); the dependent measures were S-nitrosylated NSF levels, nNOS levels and NO content in NAc. Half of the rats underwent saline injections $(0.9 \%, 1 \mathrm{ml} / \mathrm{kg})$, whereas the other rats received cocaine injections $(15 \mathrm{mg} / \mathrm{kg}$ ) once per day on seven consecutive days. On each pretreatment day, each rat was placed in locomotion cages $(45 \times 45 \mathrm{~cm})$. The NAc (core and shell) were removed for assay $14 \mathrm{~d}$ after the last pretreatment injection (WD14). In each experimental condition, some rats ( $n=4$ per group) were used for S-nitrosylation assay, some rats ( $n=6$ per group) were used for Western blot assays and the other rats ( $n=5$ per group) were used for NO assay.

Experiment 7: Effect of bath application of NO donor on surface expression of GluR2, S-nitrosylated NSF levels, and GluR2-NSF interactions in $N A c$. A finding in Experiment 4 was that withdrawal from repeated cocaine injections increases S-nitrosylation of NSF and NO content in the NAc. We determined whether exogenous NO could further influence surface GluR2 expression, S-nitrosylated NSF levels and GluR2-NSF interactions in NAc. We used two groups of rats ( $n=14$ per group) in an experimental design that included the between-subjects factor of drug (Vehicle, SNAP). The dependent measures were surface expression of GluR2, S-nitrosylated NSF levels, and GluR2-NSF interactions. All rats received cocaine injections ( $15 \mathrm{mg} / \mathrm{kg}$ ) once per day on seven consecutive days and withdrawal for $14 \mathrm{~d}$. On each pretreatment day, each rat was placed in locomotion cages $(45 \times 45 \mathrm{~cm})$. NAc slices from cocaineexposed rats were incubated with SNAP $(100 \mu \mathrm{M})$ or Vehicle for $30 \mathrm{~min}$ before assays. In each experimental condition, some rats $(n=5$ per group) were used for S-nitrosylation assay, some rats ( $n=4$ per group) were used for coimmunoprecipitation and the other rats $(n=5$ per group) were used for $\mathrm{BS}^{3}$ cross-linked.

To determine whether exogenous NO promoted the surface expression of GluR2 by GluR2-NSF interactions, we used another two groups of rats ( $n=7$ per group) in an experimental design that included the between-subjects factor of drug (TAT-pep + SNAP, TAT-pep-R845A+ SNAP); the dependent measure was the GluR2 surface expression. All rats received cocaine injections ( $15 \mathrm{mg} / \mathrm{kg}$ ) once per day on seven consecutive days and withdrawal for $14 \mathrm{~d}$. On each pretreatment day, each rat was placed in locomotion cages $(45 \times 45 \mathrm{~cm})$. NAc slices from cocaineexposed rats were incubated with TAT-pep $(100 \mu \mathrm{M})$ or TAT-pep-R845A $(100 \mu \mathrm{M})$ for $60 \mathrm{~min}$ before $\mathrm{BS}^{3}$ cross-linked; SNAP $(100 \mu \mathrm{M})$ was applied for 30 min before $\mathrm{BS}^{3}$ cross-linked.

Experiment 8: Effect of $\mathrm{NO}$ donor alone on spontaneous motor activity. We determined whether NO donor alone affected the spontaneous motor activity. For this purpose, we used two groups of rats ( $n=5-6$ per group) in an experimental design that included the between-subjects factor of SNAP ( 0 and $1 \mu \mathrm{g}$ per side). The dependent measure was travel distance. All rats received cocaine injections $(15 \mathrm{mg} / \mathrm{kg}$ ) once per day on seven consecutive days. On each pretreatment day, each rat was placed in locomotion cages $(45 \times 45 \mathrm{~cm})$. Fourteen days after the last pretreatment injection (WD14), we assessed spontaneous motor activity for $40 \mathrm{~min}$ immediately after bilateral injection with aCSF or SNAP ( $1 \mu \mathrm{g}$ per side) into NAc.

Experiment 9: Effect of $\mathrm{NO}$ donor on the expression of behavioral sensitization. We then determined whether the biochemical remodeling of surface GluR2 by NO donor led to the changes in behavioral sensitivity to cocaine. We used six groups of rats ( $n=6-12$ per group) in an experimental design that included the between-subjects factors of $\operatorname{SNAP}(0,0.5$ and $1 \mu \mathrm{g}$ ) and cocaine challenge ( 0 and $10 \mathrm{mg} / \mathrm{kg})$. The dependent measure was travel distance. All rats received cocaine injections $(15 \mathrm{mg} / \mathrm{kg})$ once per day on seven consecutive days. On each pretreatment day, each rat was placed in locomotion cages $(45 \times 45 \mathrm{~cm})$. Fourteen days after the last pretreatment injection (WD14), the rats were bilaterally injected with aCSF, SNAP ( $0.5 \mu$ g per side), or SNAP ( $1 \mu$ g per side) into NAc and assessed cocaine-induced locomotor $(0$ and $10 \mathrm{mg} / \mathrm{kg})$ sensitization after $30 \mathrm{~min}$.

Experiment 10: Effect of nitrosylating agent $\mathrm{NaNO}_{2}$ on the expression of behavioral sensitization. We determined whether sodium nitrite (NaNO2) could mimic the effect of $\mathrm{NO}$ donor in vivo. We used four groups of rats ( $n=8-9$ per group) in an experimental design that included the between-subjects factors of $\mathrm{NaNO}_{2}(0,5 \mu \mathrm{g}$ per side) and cocaine challenge $(0$ and $10 \mathrm{mg} / \mathrm{kg})$. The dependent measure was travel distance. All rats received cocaine injections $(15 \mathrm{mg} / \mathrm{kg})$ once per day on seven consecutive days. On each pretreatment day, each rat was placed in locomotion cages $(45 \times 45 \mathrm{~cm})$. Fourteen days after the last pretreatment injection (WD14), the rats were bilaterally injected with aCSF or $\mathrm{NaNO}_{2}$ (5 $\mu$ g per side) into NAc and assessed cocaine ( 0 and $10 \mathrm{mg} / \mathrm{kg}$ )-induced locomotor sensitization 30 min later.

Experiment 11: Effect of NO donor on acute cocaine-induced locomotor activity. We further determined whether NO donor affected acute 
A

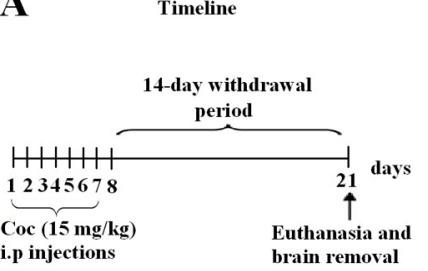

B

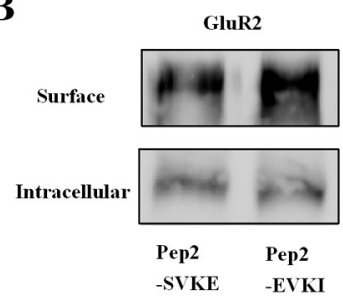

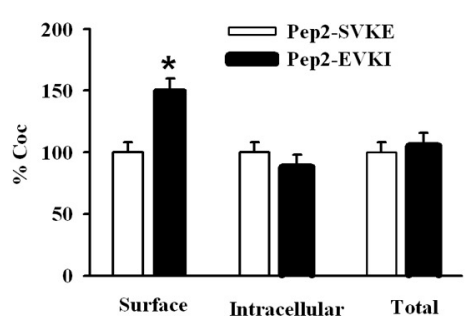

C

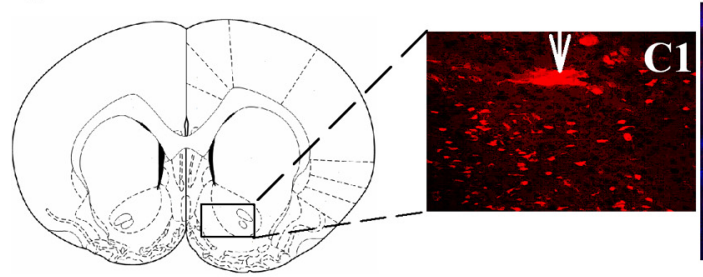

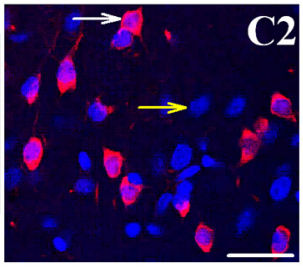

Pep2-SVKE

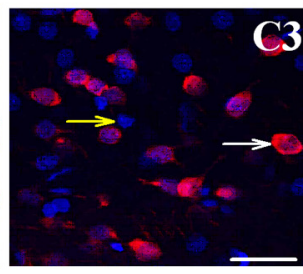

Pep2-EVKI
D

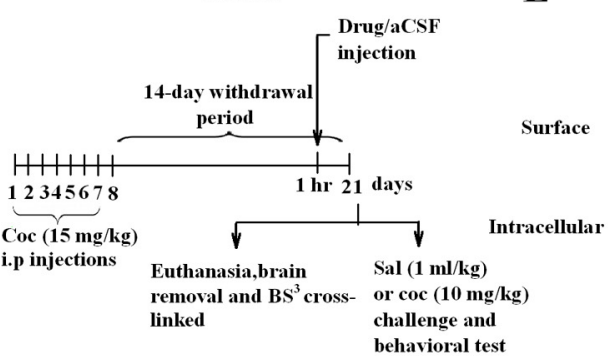

F

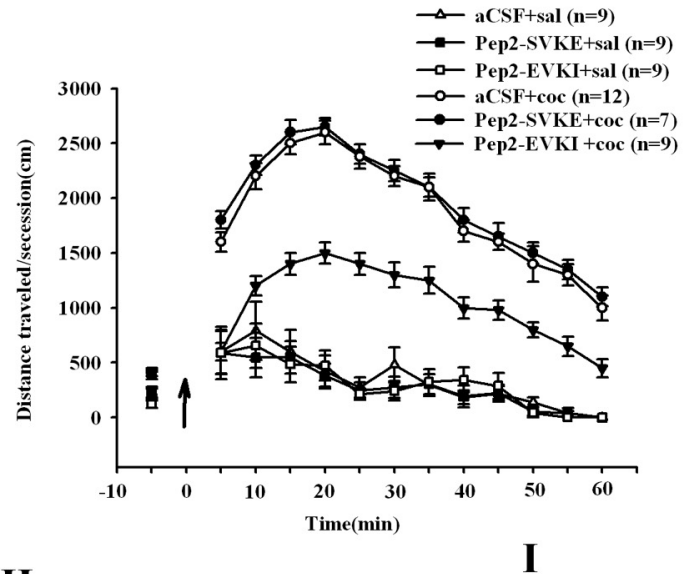

H

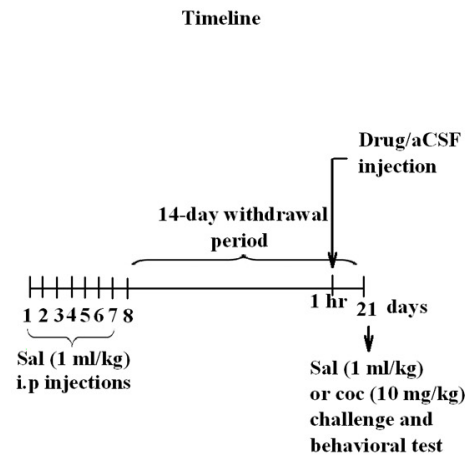

$\mathbf{E}$

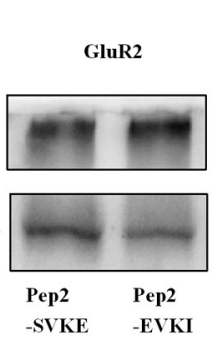

G
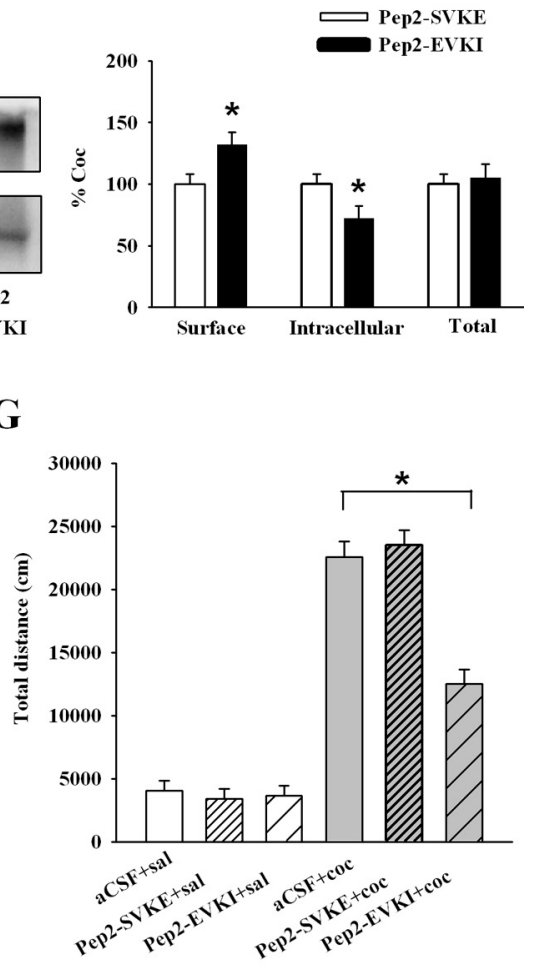

- - aCSF+sal $(\mathrm{n}=11)$

$\longrightarrow$ Pep2-SVKE+sal (n=8)

$\rightarrow$ Pep2-EVKI+sal (n=11)

$\neg$ aCSF $+\operatorname{coc}(n=10)$

$\rightarrow-$ Pep-SVKE $+\operatorname{coc}(n=9)$

$\longrightarrow-$ Pep2-EVKI $+\operatorname{coc}(n=11)$

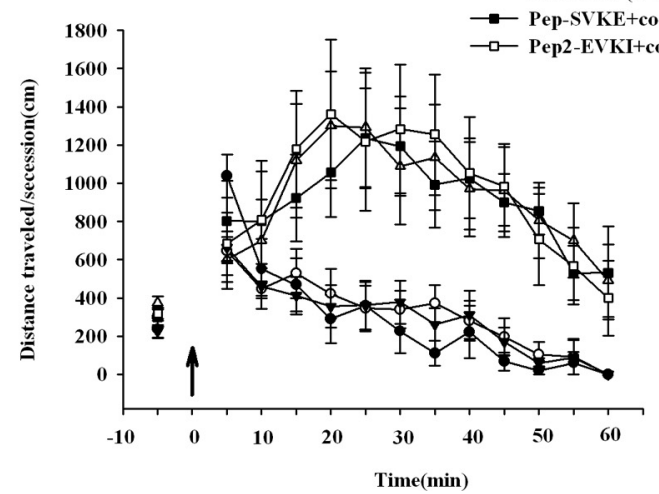


cocaine-induced locomotor activity. For this purpose, we used four groups of rats ( $n=7-13$ per group) in an experimental design that included the between-subjects factors of SNAP $(0$ and $1 \mu \mathrm{g}$ per side $)$ and acute cocaine $(0$ and $10 \mathrm{mg} / \mathrm{kg})$ administration. The dependent measure was travel distance. All rats were placed in locomotion cages $(45 \times 45 \mathrm{~cm})$ for $1 \mathrm{~h}$ habituation. The rats were bilaterally injected with aCSF or SNAP ( $1 \mu \mathrm{g}$ per side) into NAc and assessed acute cocaine-induced ( 0 and 10 $\mathrm{mg} / \mathrm{kg}$ ) locomotor activity $30 \mathrm{~min}$ later.

Experiment 12: Effect of $\mathrm{NaNO}_{2}$ on acute cocaine-induced locomotor activity. We further determined whether $\mathrm{NaNO}_{2}$ affected acute cocaineinduced locomotor activity. For this purpose, we used four groups of rats ( $n=10-11$ per group) in an experimental design that included the between-subjects factors of $\mathrm{NaNO}_{2}(0$ and $5 \mu \mathrm{g}$ per side) and acute cocaine $(0$ and $10 \mathrm{mg} / \mathrm{kg})$ administration. The dependent measure was travel distance. All rats were placed in locomotion cages $(45 \times 45 \mathrm{~cm})$ for $1 \mathrm{~h}$ habituation. The rats were bilaterally injected with $\mathrm{aCSF}$ or $\mathrm{NaNO}_{2}(5$ $\mu \mathrm{g}$ per side) into NAc and assessed acute cocaine-induced ( 0 and 10 $\mathrm{mg} / \mathrm{kg}$ ) locomotor activity $30 \mathrm{~min}$ later.

Experiment 13: Effect of TAT-pep-R845A on the role of NO donor in the expression of behavioral sensitization. We determined whether interactions of NSF-GluR2 were required for the role of NO donor in the expression of behavioral sensitization. For this purpose, we used eight groups of rats ( $n=5-11$ per group) in an experimental design that included the between-subjects factors of drug (aCSF and SNAP) and peptides (TAT-pep, TAT-pep-R845A), and cocaine challenge ( 0 and 10 $\mathrm{mg} / \mathrm{kg}$ ). The dependent measure was travel distance. All rats received cocaine injections $(15 \mathrm{mg} / \mathrm{kg}$ ) once per day on seven consecutive days and withdrawal for $14 \mathrm{~d}$. On each pretreatment day, each rat was placed in locomotion cages $(45 \times 45 \mathrm{~cm})$. TAT-pep $(25 \mu \mathrm{g}$ per side $)$ or TATpep-R845A ( $25 \mu \mathrm{g}$ per side) was bilaterally injected into NAc $60 \mathrm{~min}$ before cocaine challenge ( 0 and $10 \mathrm{mg} / \mathrm{kg}$ ). SNAP ( $1 \mu \mathrm{g}$ per side) or aCSF $(0.5 \mu$ l per side) was bilaterally injected into NAc $30 \mathrm{~min}$ before cocaine challenge ( 0 and $10 \mathrm{mg} / \mathrm{kg}$ ).

Experiment 14: Effect of NO donor on the expression of cocaine CPP. We determined whether NO donor affected the expression of cocaineinduced CPP. For this purpose, we used two groups of rats $(n=5-7$ per group) in an experimental design that included the between-subject factor of drug (aCSF, SNAP) and the within-subject factor of test phase (pretraining baseline preference, post-training CPP test). The dependent measure was the CPP score. The rats were trained for cocaine-induced $\mathrm{CPP}$. One day after cocaine-induced CPP training, the rats were bilaterally injected with either aCSF or SNAP ( $1 \mu \mathrm{g}$ per side) into NAc and measured the expression of CPP 30 min later.

Experiment 15: Effect of NO donor on SPT. We determined whether NO donor affected sucrose preference. For this purpose, we used two groups of rats ( $n=7-8$ per group) in an experimental design that included the

$\leftarrow$

Figure 3. Increase in accumbal surface GluR2 by reducing PICK1-dependent AMPAR endocytosis prevents the expression of behavioral sensitization to cocaine. $\boldsymbol{A}, \boldsymbol{D}, \boldsymbol{H}$, Timeline of the experimental procedure. $\boldsymbol{B}$, Blocking PICK1-mediated GluR2 endocytosis by specific peptide Pep2-EVKI (100 $\mu \mathrm{M}, 30 \mathrm{~min})$ promoted surface expression of GluR2 in ex vivo slices. Data from the Pep2-EVKI group were normalized to the mean of the Pep2-SVKE group. ( $n=5$ rats for each group; ${ }^{*} p<0.05$, different from control peptide). C, Microinjection of Pep2-SVKE or Pep2-EVKI peptides led to internalization of peptides into NAc cells. The big white arrow shows the site of injection (C1). Biotin-labeled Pep2-SVKE ( $(2 ; n=4)$, or Pep2-EVKI $(\mathbf{C} ; n=4)$ were microinjected into the NAc $(50 \mu \mathrm{g} / \mu \mathrm{l}, 0.5 \mu \mathrm{l}$ per NAc). Transcellular translocation was detected by streptavidin conjugated to AlexaFluor 568 (red) and to nuclear Hoechst (blue) staining. Small white arrows indicate the positive cells (red staining and blue nuclei) and small yellow arrows indicate negative cells (blue nuclei only). E, Blocking PICK1-mediated GluR2 endocytosis by specific peptide Pep2-EVKI (100 $\mu \mathrm{m}, 30 \mathrm{~min})$ intracranial injections promoted surface expression of GluR2. Data from the Pep2-EVKI group were normalized to the mean of the Pep2-SVKE group. ( $n=7$ rats for each group; ${ }^{*} p<0.05$, different from control peptide). $\boldsymbol{F}$, Pretreatment with Pep2-EVKI for $60 \mathrm{~min}$ blocked the responses to the challenge dose (black arrow) of cocaine. $\mathbf{G}$, The bar diagram shows total travel distance in each group $(n=7-12$ rats for each group; ${ }^{*} p<0.05$, different from the other experimental groups). I, Pretreatment with Pep2-EVKI for $60 \mathrm{~min}$ did not alter acute cocaine or saline-induced (black arrow) locomotor activity. All data are mean \pm SEM. between-subject factor of drug (aCSF, SNAP). The dependent measure was the ratio of the volume of sucrose versus total volume of sucrose and water. Rats were exposed to a palatable sucrose solution $(1 \% ; \mathrm{m} / \mathrm{v})$ for $48 \mathrm{~h}$ to habit sucrose intake. One day after habituation, rats were water deprived for $6 \mathrm{~h}$ before bilaterally injected with aCSF or SNAP ( $1 \mu \mathrm{g}$ per side) into NAc. Thirty minutes later, the rats were presented with two identical bottles; one was filled with sucrose solution and the other with water for $1 \mathrm{~h}$.

Experiment 16: Effect of $\mathrm{NO}$ donor on the expression of CPA. We determined whether NO donor affected conditioned taste aversion. For this purpose, we used four groups of rats ( $n=8-9$ per group) in an experimental design that included the between-subjects factors of drug (aCSF, SNAP) and CTA conditioning ( $0.05 \mathrm{M} \mathrm{LiCl}, 0.15 \mathrm{M} \mathrm{LiCl})$. The dependent measure was AI. Two days after weak $(0.05 \mathrm{M} \mathrm{LiCl})$ or strong $(0.15 \mathrm{M} \mathrm{LiCl})$ CTA training, the rats were bilaterally injected with aCSF or SNAP $(1 \mu \mathrm{g}$ per side) into NAc. Thirty minutes later, the rats were presented with a random array of six pipettes, three filled with saccharin and three filled with water for $10 \mathrm{~min}$.

\section{Data analysis}

Data from experiments were analyzed with the statistical program SPSS. Data were analyzed with ANOVAs using the appropriate betweenand within-subjects factors for the different experiments (see Specific experiments, and Results). Comparison between two groups was evaluated by a two-sided and unpaired Student's $t$ test. Differences between experimental conditions were considered statistically significant when $p<0.05$. Data are presented as mean \pm SEM.

\section{Results}

\section{Increased NSF-GluR2 interactions in the NAc after} withdrawal from cocaine

We first established a rat model of behavioral sensitization by repeated cocaine injection (Bachtell and Self, 2008; Ferrario et al., 2010). Rats were injected with saline or cocaine $(15 \mathrm{mg} / \mathrm{kg})$ and were repeatedly tested for 1-7 $\mathrm{d}$. We analyzed the locomotor activity using repeated-measures ANOVA with the betweensubjects factor of cocaine dose ( 0 and $15 \mathrm{mg} / \mathrm{kg}$ ) and the withinsubjects factor of test day (1-7). Locomotor activity increased across days of cocaine $(15 \mathrm{mg} / \mathrm{kg})$ injection, data analysis revealed significant effects of cocaine dose $\left(F_{(1,18)}=73.5, p<0.01\right)$, test day $\left(F_{(6,13)}=3.328, p<0.05\right)$, and an interaction between these two factors $\left(F_{(6,13)}=4.5, p<0.05\right)$. And cocaine challenge $(10$ $\mathrm{mg} / \mathrm{kg}$ ) at day 14 of withdrawal induced a much greater locomotor response in cocaine-pretreated rats than that in saline group (Sal: 8801.58 \pm 697.21; Coc: $22965.56 \pm 1042.67$; Student's $t$ test, $p<0.05$ vs saline; Fig. $1 A$ ). In Experiment 1, we determined the effect of withdrawal from repeated cocaine exposure on surface expression of GluR1/2 and NSF-GluR2 interactions in NAc. In rats killed $14 \mathrm{~d}$ after the last cocaine or saline injection (Fig. $1 B$ ), the surface expression of GluR1 (Sal: $100 \pm 11.21$; Coc: $152.23 \pm$ 12.67), and GluR2 (Sal: $100 \pm 14.56$; Coc: $158.06 \pm 15.11$ ) were significantly increased in rats that developed behavioral sensitization compared with saline controls (Student's $t$ test, $p<0.05$ vs saline; Fig. $1 C, D)$. These results were consistent with previous study showing that an increase in cell surface expression of GluR1/2-containing AMPARs in the NAc of cocaine-sensitized rats (Ferrario et al., 2010). Accordingly, we used immunostaining experiments and found an increase in the proportion of GluR2 colocalized with NSF in NAc neurons of sensitized rats compared with control rats (Fig. 1E; white arrows). Our coimmunoprecipitation results revealed that NSF-GluR2 interactions were significantly higher in cocaine-exposed rats than in saline-exposed ones (Sal: $100 \pm 16.82$; Coc: $155.38 \pm 19.74$; Student's $t$ test, $p<$ 0.05 vs saline; Fig. $1 F$ ), providing further evidence for an increase in the NSF-GluR2 binding in NAc neurons after withdrawal from cocaine. 
A

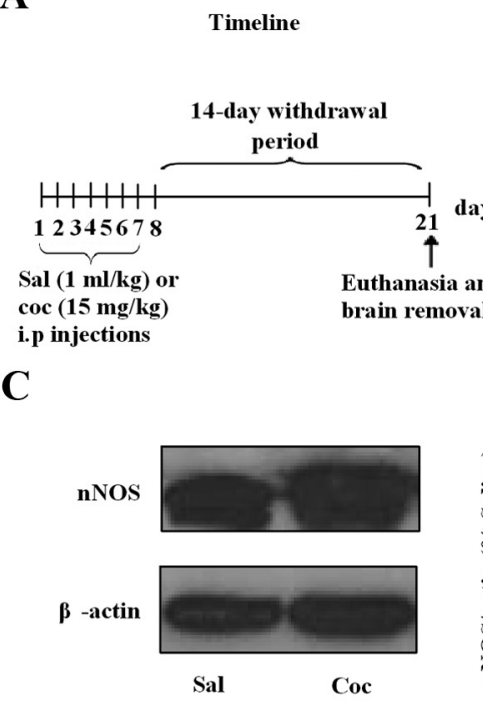

B

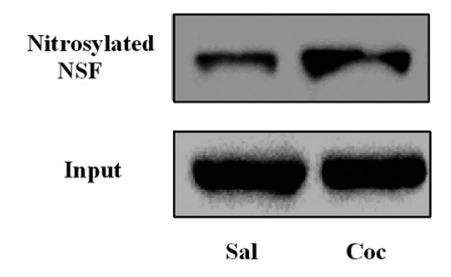

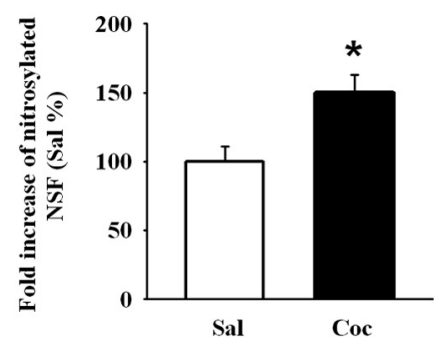

D
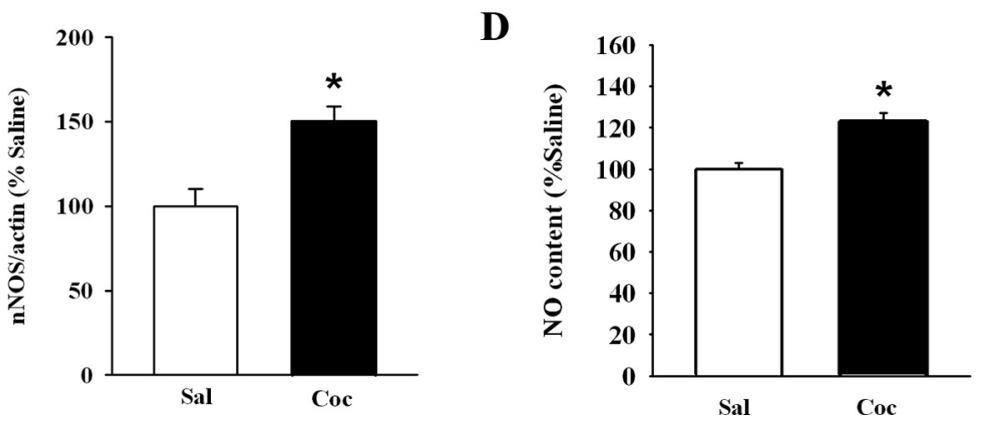

Figure 4. Withdrawal from repeated cocaine injections increases S-nitrosylation of NSF and NO content in the NAc. $A$, Timeline of the experimental procedure. $\boldsymbol{B}$, Withdrawn from cocaine increased S-nitrosylation of NSF in the NAc. Data were first expressed as the ratio of the $S$-nitrosylated NSF to input. Then, data from the cocaine group were normalized to the mean of the saline group. ( $n=4$ rats for each group; ${ }^{*} p<0.05$ vs saline). $C$, Withdrawal from cocaine increased the expression of nNOS in the NAc. Data were first expressed as the ratio of the nNOS to $\beta$-actin. Then, data from the cocaine group were normalized to the mean of the saline group. ( $n=6$ rats for each group; ${ }^{*} p<0.05$ vs saline). $\boldsymbol{D}$, Withdrawal from cocaine increased the N0 content in the NAc. Data from the cocaine group were normalized to the mean of the saline group. ( $n=5$ rats for each group; ${ }^{*} p<0.05$ vs saline). All data are mean \pm SEM.

\section{NSF-GluR2 interaction disrupting peptide reduces the surface expression of GluR2 and increases the expression of locomotor sensitization to cocaine}

In Experiment 2, we used the specific NSF-GluR2 interaction blocking peptide (pep-R845A conjugated to TAT; Joels and Lamprecht, 2010) to determine the role of the increased binding of NSF to GluR2 in cocaine sensitization. In rats killed $14 \mathrm{~d}$ after the last cocaine injection (Fig. 2A), the level of surface GluR2 was decreased after bath incubation of NAc slices from cocaineexposed rats with TAT-pep-R845A (ANOVA, $F_{(1,23)}=30.71, p<$ 0.01, for drug; TAT-pep, TAT-pep-R845A; Fig. 2B). To determine whether the effect of TAT-pep-R845A incubation occurs locally in the NAc, as shown in Figure 2D, we performed a microinjection study in cocaine-exposed rats. Intracranial injections of this peptide into the NAc produced the same effect as that seen when peptides were bath-applied to slices (ANOVA, $F_{(1,23)}=$ $8.32, p<0.01$ ), for drugs TAT-pep, TAT-pep-R845A; Fig. $2 E$ ). In behavioral test, rats were decapitated after behavioral experiments to check the localization of cannulas, and only rats with correct localization were enrolled in the statistics (Fig. 2C1, white arrow). Microinjection of TAT-pep or TAT-pep-R845A peptides into NAc led to their internalization into cells 30 min later, and immunostaining results showed equal distribution of the peptides in neurons (Fig. 2C2,C3, white arrows). To evaluate a direct effect of TAT-pep-R845A on locomotor sensitization to cocaine, the cocaine-exposed rats were microinjected with TAT-pepR845A into NAc (Fig. 2D; the experimental procedure of challenge). It was found that TAT-pep-R845A significantly increased the response to cocaine (ANOVA, $F_{(2,52)}=4.796, p=0.012$, for drugs aCSF, TAT-pep, and TAT-pep-R845A; $F_{(1,52)}=207.462$, $p<0.01$, for cocaine challenge, 0 and $10 \mathrm{mg} / \mathrm{kg}$; Fig. $2 F, G$ ). We next examined whether the effect was specific to the cocaineexposed rats. In Experiment 3, injection of TAT-pep-R845A into NAc (Fig. 2H) had no effect on locomotor activity induced by cocaine in saline-exposed rats (Fig. $2 I$ ).
Increase in accumbal surface expression of GluR2 by reducing PICK1-dependent AMPAR endocytosis attenuates the expression of behavioral sensitization to cocaine

The aforementioned results indicate that disrupting the increased binding of NSF to GluR2 in NAc neurons elevated the expression of behavioral sensitization to cocaine, suggesting that increased NSF-GluR2 interactions might confer protection against cocaine-related behaviors. Previous studies showed that NSF stabilized AMPARs at synapses, presumably by preventing PICK1mediated endocytosis (Hanley et al., 2002; Lee et al., 2002). We reasoned that disruption of GluR2-PICK1 interactions would mimic the role of NSF in the surface expression of GluR2. To test this hypothesis, we therefore used a peptide that specifically disrupts the interaction of GluR2 with PICK1, a molecule that promotes internalization and retains GluR2 intracellularly (Famous et al., 2008). As expected in Experiment 4, in rats killed $14 \mathrm{~d}$ after the last cocaine injection (Fig. $3 A$ ), bath incubation of NAc slices from cocaine-exposed rats with Pep2-EVKI (100 $\mu \mathrm{M}, 30 \mathrm{~min})$ increased the level of surface expression of GluR2 compared with the Pep2-SVKE controls (ANOVA, $F_{(1,22)}=7.506, p<0.05$, for drugs Pep2-SVKE, Pep2-EVKI; Fig. 3B). To determine whether the effect of Pep2-EVKI incubation occurs locally in the NAc, as shown in Figure $3 D$, we performed a microinjection study in cocaine-exposed rats. Intracranial injections of this peptide into the NAc produced the same effect as that seen when peptides were bath-applied to slices (ANOVA, $F_{(1,22)}=7.181, p<0.05$, for drugs Pep2-SVKE, Pep2-EVKI; Fig. 3E). To investigate whether Pep2-EVKI had effect on locomotor sensitization to cocaine, Pep2-EVKI, Pep2-SVKE, or aCSF were microinjected into the NAc $1 \mathrm{~h}$ before a systemic injection of cocaine challenge on WD14 (Fig. 3D; the experimental procedure of challenge). Immunostaining also showed correct cannula localization (Fig. 3C1, white arrow) and equal distribution of the peptides in neurons (Fig. 3C2,C3, white arrows). Behavioral results showed that rats pretreated with Pep2-EVKI significantly attenuated the respon- 
siveness to cocaine (ANOVA, $F_{(2,48)}=$ $4.583, p=0.015$, for drugs aCSF, Pep2SVKE, and Pep2-EVKI; $F_{(1,48)}=44.107$, $p<0.01$, for cocaine challenge, 0 and 10 $\mathrm{mg} / \mathrm{kg}$; Fig. $3 F, G)$. As expected in Experiment 5, in saline-exposed rats (Fig. $3 H$ ), Pep2-EVKI did not cause the behavioral effects (Fig. 3I). These results suggested that the impairment of endocytosis of GluR2-containing AMPARs disrupted the response of rats to cocaine. These findings indicate that promotion of the movement of GluR2-containing AMPARs to the cell surface of accumbal neurons attenuate the expression of behavioral sensitization to cocaine.

\section{S-nitrosylation of NSF enhances the interactions of NSF and GluR2}

Because the NSF-GluR2 interactions have been proposed to influence the behavioral sensitization through regulation of the surface expression of GluR2. How might cocaine treatment increase NSF-GluR2 interactions in the NAc? In Experiment 6, we examined a possible relationship between the NSF-GluR2 interactions and S-nitrosylation of NSF, with the hypothesis that withdrawal from repeated cocaine increased the S-nitrosylation of NSF. In cocaine or saline-exposed rats (Fig. $4 A$ ), we used the biotin-switch technique and found that the S-nitrosylated NSF level in the NAc of cocaine-exposed rats was increased (Sal: $100 \pm 12.33$; Coc: $151.89 \pm$ 13.71; Student's $t$ test, $p<0.05$ vs saline; Fig. $4 B$ ). In addition, we detected neuronal NO synthase (nNOS) in the NAc and found that withdrawal from cocaine significantly increased nNOS expression (Sal: $100 \pm 14.03$; Coc: $149.81 \pm 11.01$; Student's $t$ test, $p<0.05$ vs saline; Fig. $4 C)$. Consistent with these Western blot results, nitrite content in the NAc also showed a slight but significant increase in cocaine rats (Sal: $100 \pm 8.28$; Coc: $122.78 \pm 7.71$; Student's $t$ test, $p<0.05$ vs saline; Fig. 4D). These results suggest that withdrawal from cocaine promote S-nitrosylation of NSF, which is associated with the increased level of NO in the NAc.

\section{Exogenous NO promotes the surface expression of GluR 2 containing-} AMPARs in the NAc and inhibits cocaine sensitization via $S$-nitrosylation of NSF

In Experiment 7, we therefore asked whether exogenous NO could influence the NSF-GluR2 interactions to attenuate cocaine-induced locomotor sensitization through regulation of GluR2 surface expression. In cocaine-exposed rats (Fig. 5A), treatment of NAc slices with SNAP (100 $\mu \mathrm{M}, 30 \mathrm{~min})$ significantly

A

D

Intracellular

E
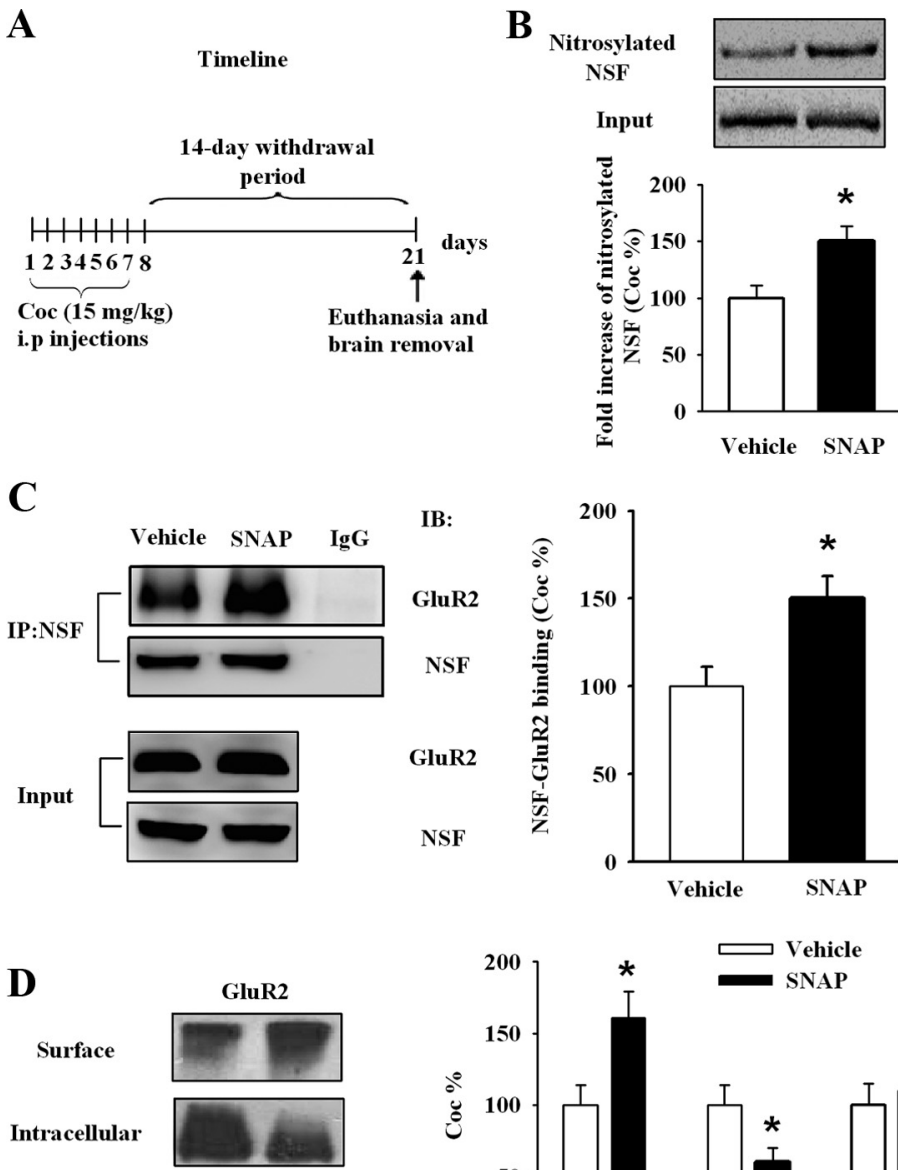

Vehicle SNAP

GluR2

NSF
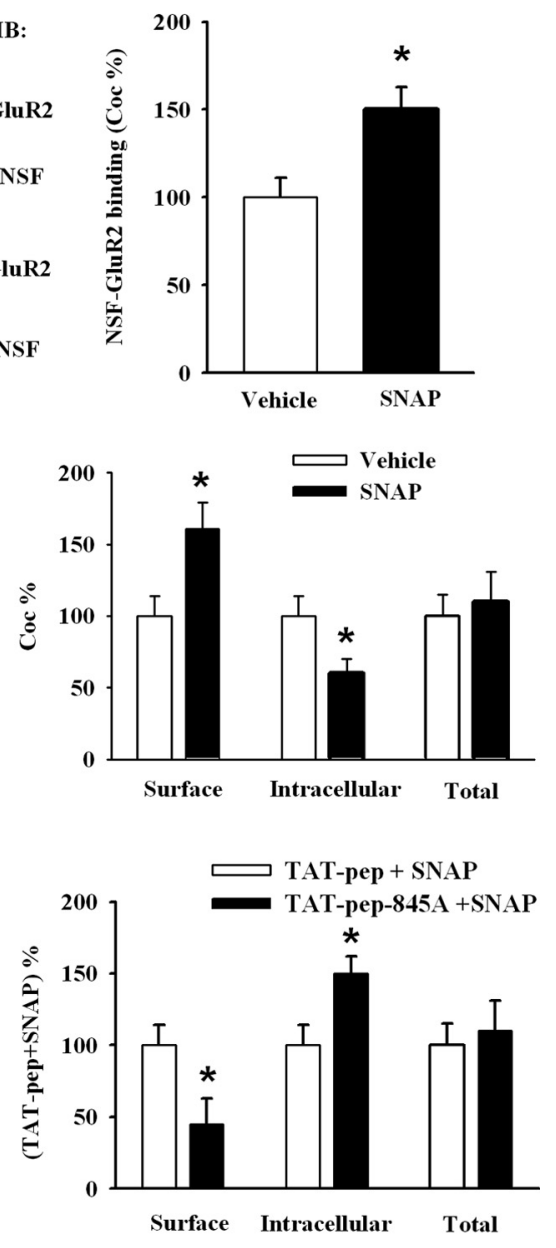

Figure 5. Bath application of NO donor upregulates the surface expression of GluR2 by S-nitrosylation of NSF and enhances the interaction of GluR2-NSF. A, Timeline of the experimental procedure. B, SNAP (100 $\mu \mathrm{m}, 30 \mathrm{~min})$ increased S-nitrosylation of NSF in NAc slices from cocaine rats. Data were first expressed as the ratio of the S-nitrosylated NSF to input. Then, data from the SNAP group were normalized to the mean of the vehicle group. ( $n=5$ rats for each group; ${ }^{*} p<0.05$ vs vehicle). C, SNAP (100 $\mu$ M, 30 min) obviously increased GluR2-NSF interactions in NAc slices from cocaine rats. Data were first expressed as the ratio of the protein in the immunocomplex (Co-IP) to total lysate. Then, data from the SNAP group were normalized to the mean of the vehicle group. ( $n=4$ rats for each group; ${ }^{*} p<0.05$ vs vehicle). D, SNAP (100 $\mu \mathrm{m}, 30 \mathrm{~min}$ ) obviously increased surface GluR2 in NAc slices from cocaine rats. Data from the SNAP group were normalized to the mean of the vehicle group. ( $n=5$ rats for each group; ${ }^{*} p<$ 0.05 vs vehicle). $\boldsymbol{E}$, TAT-pep-R845A (100 $\mu \mathrm{m}, 30 \mathrm{~min}$ ) that disrupted the interaction of NSF-GluR2 prevented the role of N0 in surface GluR2 expression. Data from the (TAT-pep-R845A + SNAP) group were normalized to the mean of the (TAT-pep + SNAP) group. $\left(n=7\right.$ rats for each group; ${ }^{*} p<0.05$ vs TAT-pep + SNAP). All data are mean \pm SEM.

increased the level of NSF nitrosylation (vehicle: $100 \pm 13.09$; SNAP: $153.19 \pm 15.45$; Student's $t$ test, $p<0.05$ vs vehicle; Fig. $5 B$ ) and augmented NSF-GluR2 binding in cocaine-exposed rats (vehicle: $100 \pm 15.33$; SNAP: $150.11 \pm 13.21$; Student's $t$ test, $p<$ 0.05 vs vehicle; Fig. $5 C$ ). Surface GluR2 expression in the NAc was 
A

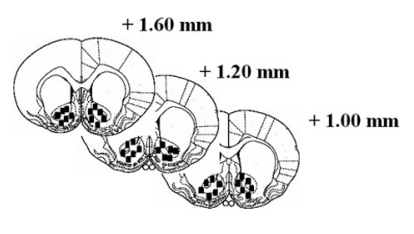

B

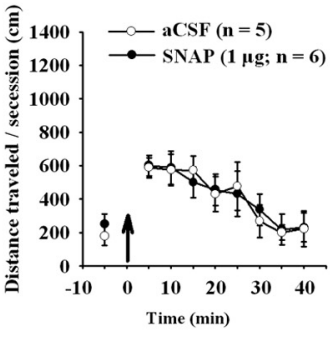

D

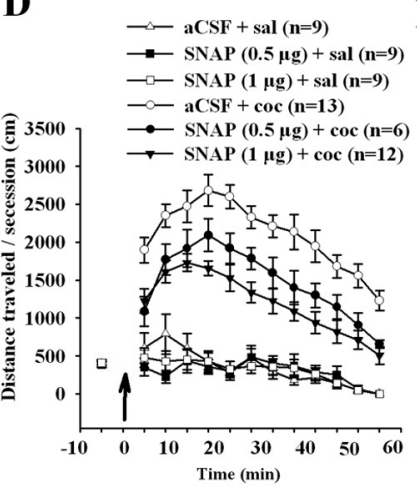

\section{G}

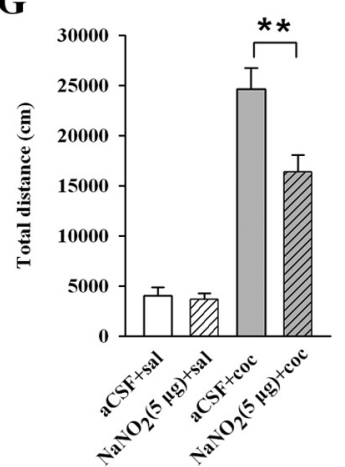

$\mathbf{J}$

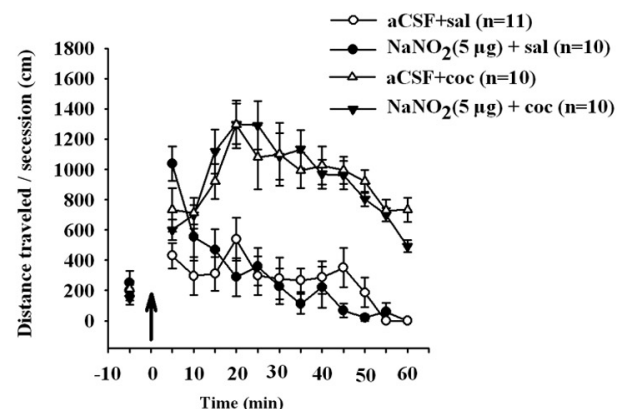

C

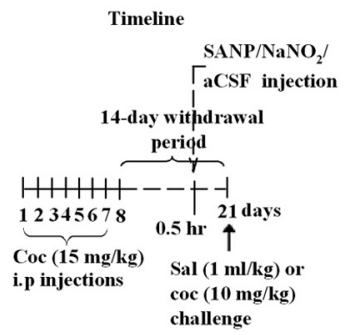

E

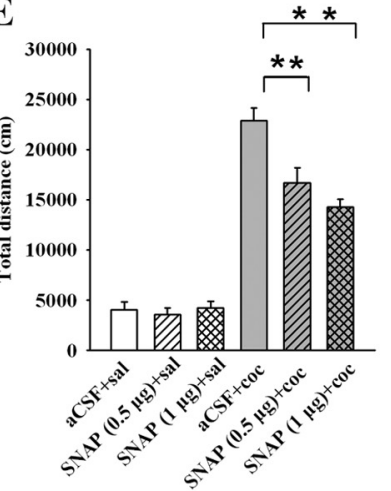

H

H Timeline $\mathrm{SANP} / \mathrm{NaNO}_{2} /$
$\Gamma_{\text {aCSF injection }}$

14-day withdrawal

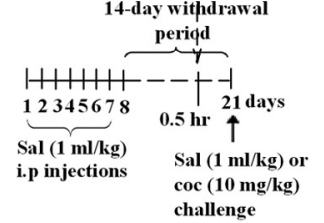

K
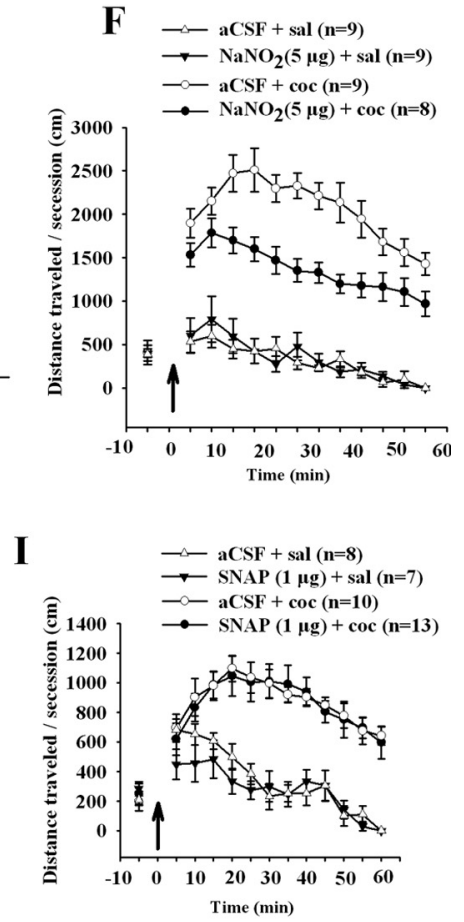

Timeline

$\longrightarrow-\operatorname{aCSF}+\operatorname{sal}(n=8)$

M

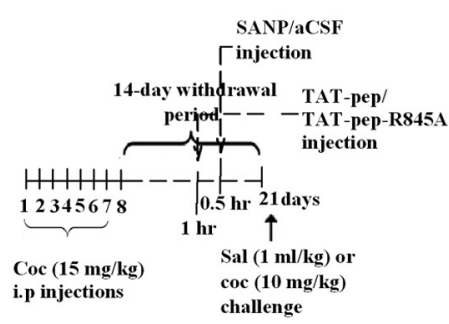

$\mathbf{L}$

$\longrightarrow-\operatorname{SNAP}(1 \mu \mathrm{g})+\operatorname{sal}(\mathrm{n}=6)$

$\rightarrow$ TAT-pep + SNAP $(1 \mu \mathrm{g})+\operatorname{sal}(\mathrm{n}=7)$

- TAT-pep-845A + SNAP(1 $\mu \mathrm{g})+\operatorname{sal}(\mathrm{n}=8)$ $\multimap-a C S F+\operatorname{coc}(n=8)$

$\rightarrow \operatorname{SNAP}(1 \mu \mathrm{g})+\operatorname{coc}(\mathrm{n}=6)$

$\rightarrow$ TAT-pep $+\operatorname{SNAP}(1 \mu \mathrm{g})+\operatorname{coc}(\mathrm{n}=5)$
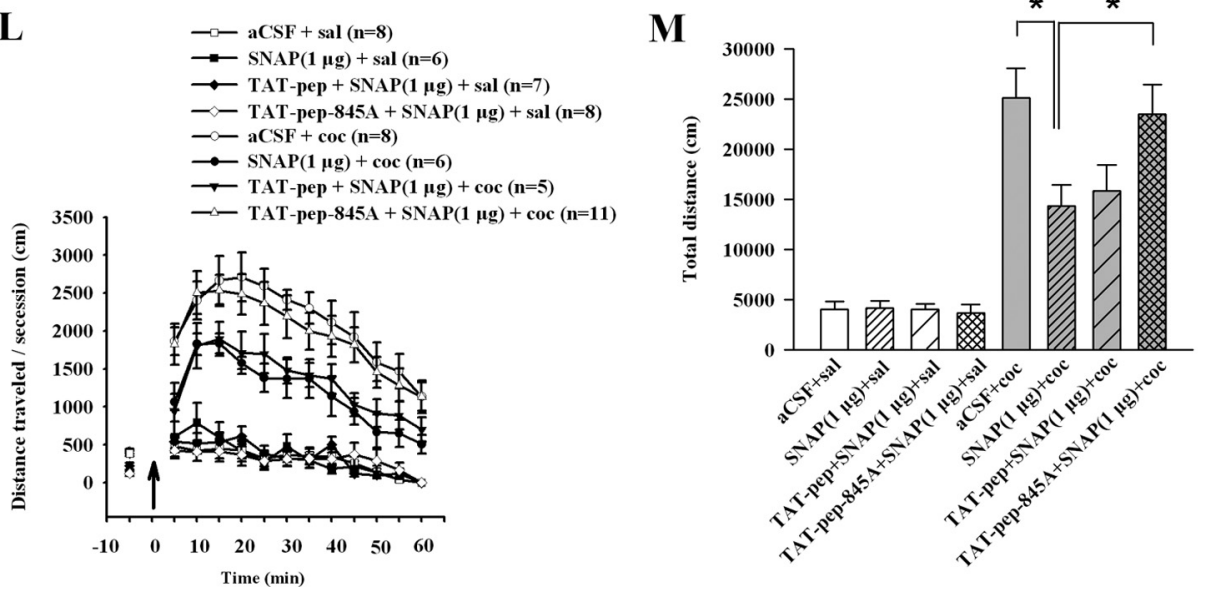
also obviously increased after treatment with SNAP $(100 \mu \mathrm{M}, 30$ $\min$ ) in cocaine-exposed rats (vehicle: $100 \pm 19.33$; SNAP: $163.89 \pm 22.45$; Student's $t$ test, $p<0.05$ vs vehicle; Fig. $5 D$ ). Compared with control peptide TAT-pep, TAT-pep-R845A (100 $\mu \mathrm{M}, 30 \mathrm{~min}$ ) pretreatment obviously prevented SNAP-induced increase in surface GluR2 expression (TAT-pep+SNAP: $100 \pm$ 18.67; TAT-pep-R845A+SNAP: $45.07 \pm 22.33$; Student's $t$ test, $p<0.05$ vs TAT-pep+SNAP; Fig. $5 E)$.

We then determined whether the biochemical remodeling of surface GluR2 led to the changes in behavioral sensitivity to cocaine. Rats received SNAP or aCSF displayed indistinguishable spontaneous motor activity in Experiment 8 (Fig. 6B). As described in Figure $6 C$, intra-accumbal infusion of SNAP ( 0.5 or 1 $\mu \mathrm{g}$ per side) $30 \mathrm{~min}$ before cocaine challenge dose-dependently attenuated locomotor behavior in Experiment 9 (ANOVA, $F_{(2,59)}=10.715, p<0.01$, for SNAP 0, 0.5, and $1 \mu \mathrm{g} ; F_{(1,59)}=$ 108.847, $p<0.01$, for cocaine challenge, 0 and $10 \mathrm{mg} / \mathrm{kg}$; Fig. $6 D, E)$. In Experiment 10, intra-accumbal infusion of nitrosylating agent sodium nitrite $\left(\mathrm{NaNO}_{2}, 5 \mu \mathrm{g}\right)$ also produced similar effect $\left(\right.$ ANOVA, $F_{(1,35)}=12.814, p<0.01$, for $\mathrm{NaNO}_{2}, 0,5 \mu$ g per side; $F_{(1,35)}=170.021, p<0.01$, for cocaine challenge, 0 and 10 $\mathrm{mg} / \mathrm{kg}$; Fig. $6 F, G)$, confirming that $S$-nitrosylation mediates the role of SNAP. However, intra-accumbal infusion of SNAP or $\mathrm{NaNO}_{2}$ (Fig. $6 \mathrm{H}$ ) before acute treatment with cocaine had no effect on locomotor behavior in Experiments 11 and 12 (Fig. $6 I, J)$. These results suggested that NO specifically attenuated the expression of behavioral sensitization. We next asked whether interactions of NSF-GluR2 were required. As described in Figure $6 \mathrm{~K}$, we performed Experiment 13 and found that preinfusion of TAT-pep-R845A into NAc eliminated the attenuation of behavioral sensitization by SNAP $\left(1 \mu \mathrm{g}\right.$ per side; ANOVA, $F_{(3,61)}=$ $2.972, p<0.05$, for SNAP $\times$ TAT-pep-R845A; $F_{(1,61)}=171.977$, $p<0.01$, for cocaine challenge, 0 and $10 \mathrm{mg} / \mathrm{kg}$; Fig. $6 \mathrm{~L}, M)$. These results establish that $\mathrm{NO}$-induced attenuation of the expression of behavioral sensitization was mediated by NSF S-nitrosylation and consequent increase in surface GluR2 through NSF-GluR2 interactions.

\section{Accumbal application of NO donor attenuates the expression of cocaine-induced CPP, but not sucrose preference test or conditioned taste aversion}

Sensitization to the locomotor-stimulating effects of psychostimulants has been suggested as a behavioral mechanism that

$\leftarrow$

Figure 6. Nitrosylating agent prevents the expression of behavioral sensitization by enhancing NSF-GluR2 interactions. $A$, Maps illustrating the location of microinjection sites in the NAc. $B$, Bilateral accumbal injection (black arrow) of SNAP (1 $\mu \mathrm{g}$ per side) did not alter spontaneous motor activity. $\boldsymbol{C}, \boldsymbol{H}, \boldsymbol{K}$, Timeline of the experimental procedure. $\boldsymbol{D}$, Intra-accumbal injection of SNAP ( 0.5 or $1 \mu \mathrm{g}$ per side, $30 \mathrm{~min}$ before cocaine challenge) dose-dependently attenuated cocaine but not saline-induced (black arrow) behavioral activity in cocaine rats. $E$, Bar diagram shows total traveled distance in each group from $D\left(n=6-12\right.$ rats for each group; ${ }^{* *} p<0.01$, different from the other experimental groups). $\boldsymbol{F}$, Administration of $\mathrm{NaNO}_{2}(5 \mu \mathrm{g}$ per side) weakened cocaine but not saline-induced (black arrow) behavioral sensitization in cocaine rats. $\boldsymbol{G}$, Bar diagram shows total traveled distance in each group from $\boldsymbol{F}(n=8-9$ rats for each group; ${ }^{* *} p<0.01$, different from the other experimental groups). I, Administration of SNAP ( $1 \mu \mathrm{g}$ per side; $30 \mathrm{~min}$ before cocaine at $10 \mathrm{mg}$ per $\mathrm{kg}$, i.p.) did not alter acute cocaine or saline-induced (black arrow) locomotor activity. J, Administration of $\mathrm{NaNO}_{2}(5 \mu \mathrm{g}$ per side; $30 \mathrm{~min}$ before cocaine at $10 \mathrm{mg}$ per $\mathrm{kg}$, i.p.) did not alter acute cocaine or saline-induced (black arrow) locomotor activity. $L, M$, Coadministration of TAT-pep-R845A that disrupted NSF-GluR2 interaction (25 $\mu \mathrm{g}$ per side; $30 \mathrm{~min}$ before SNAP) prevented the role of $\mathrm{NO}$ in expression of behavioral sensitization, whereas control peptide TAT-pep did not affect this response. The bar diagram shows total travel distance in each group $\left(n=5-11\right.$ rats for each group; ${ }^{*} p<0.05$, different from the other experimental groups). All data are mean \pm SEM. may model aspects of human drug addiction, particularly drug craving (Robinson and Berridge, 1993) but it does not model many components of addiction (Koya et al., 2012). In Experiment 14, we assessed the effect of NO on CPP, which reflects the rewarding effect of cocaine. After cocaine CPP training, bilateral accumbal injection of SNAP ( $1 \mu \mathrm{g}$ per side) 30 min before test significantly attenuated the expression of cocaine conditioned place preference (ANOVA, $F_{(1,18)}=18.08, p<0.01$ for a SNAP effect; Fig. $7 A$ ). However, the results in Figure $7 A$ indicated that SNAP appeared to do more than just reduce CPP; it may have been aversive. To further determine the rewarding versus aversive effects of SNAP alone, we successfully established a rat model of conditioned taste aversion (Fig. 7C) and assessed the effect of accumbens SNAP injections on sucrose preference (Fig. 7B) and saccharin-LiCl-paired aversive cues (Fig. 7D). No significant effects were observed for SNAP in the sucrose preference test or conditioned taste aversion in Experiment 15 and 16 (Fig. 7B,D). Our results suggest that $\mathrm{NO}$ can attenuate the rewarding effect of cocaine, but did not appear to represent a general disruption of reward behavior or aversive behavior.

\section{Discussion}

Our study provides two key findings. First, withdrawal from repeated cocaine exposure increases NSF-GluR2 interactions and enhances NSF nitrosylation, which is associated with increased endogenous NO. Second, inhibition or further promotion of the transport of GluR2-containing AMPARs to the cell surface enhanced or attenuated cocaine-induced locomotor sensitization. Collectively, these results suggest that enhanced NSF-GluR2 interactions in the NAc in cocainesensitized rats serves as a protective mechanism to cocaineinduced locomotor sensitization.

\section{NSF-GluR2 interactions in the nucleus accumbens and the expression of behavioral sensitization to cocaine}

In the present study, we discovered a novel mechanism associated with the upregulation of GluR2-containing AMPARs after withdrawal from a sensitizing cocaine regimen. Our findings showed that WD 14 from repeated cocaine exposure increased NO content and nitrosylation of NSF in the NAc. We also found enhanced GluR2-NSF interactions, which was associated with increased surface expression of the calciumimpermeable GluR2-containing AMPARs. The present results are consistent with previous findings that surface GluR2containing AMPARs at synapses is physiologically regulated by NO via a NSF-dependent manner (Huang et al., 2005). Disruption of the increased binding of NSF to GluR2 in NAc neurons increased the expression of behavioral sensitization to cocaine, suggesting that enhanced NSF-GluR2 interactions might confer a protective mechanism against cocaine-induced sensitization. Meanwhile, our findings revealed S-nitrosylation of NSF by SNAP enhanced its binding to GluR2, and regulated the surface expression of receptor. Moreover, intra-accumbal infusion of SNAP before cocaine challenge dose-dependently attenuated locomotor behavior. The effects of exogenous NO in vitro and in vivo were blocked by a peptide, TAT-pep-R845A, that disrupt the interaction between GluR2 subunits and NSF. These results supported our hypothesis that withdrawal-induced upregulation of NSF-GluR2 interactions would be a compensatory mechanism to counteract cocaine psychomotor sensitization (Fig. 8). 

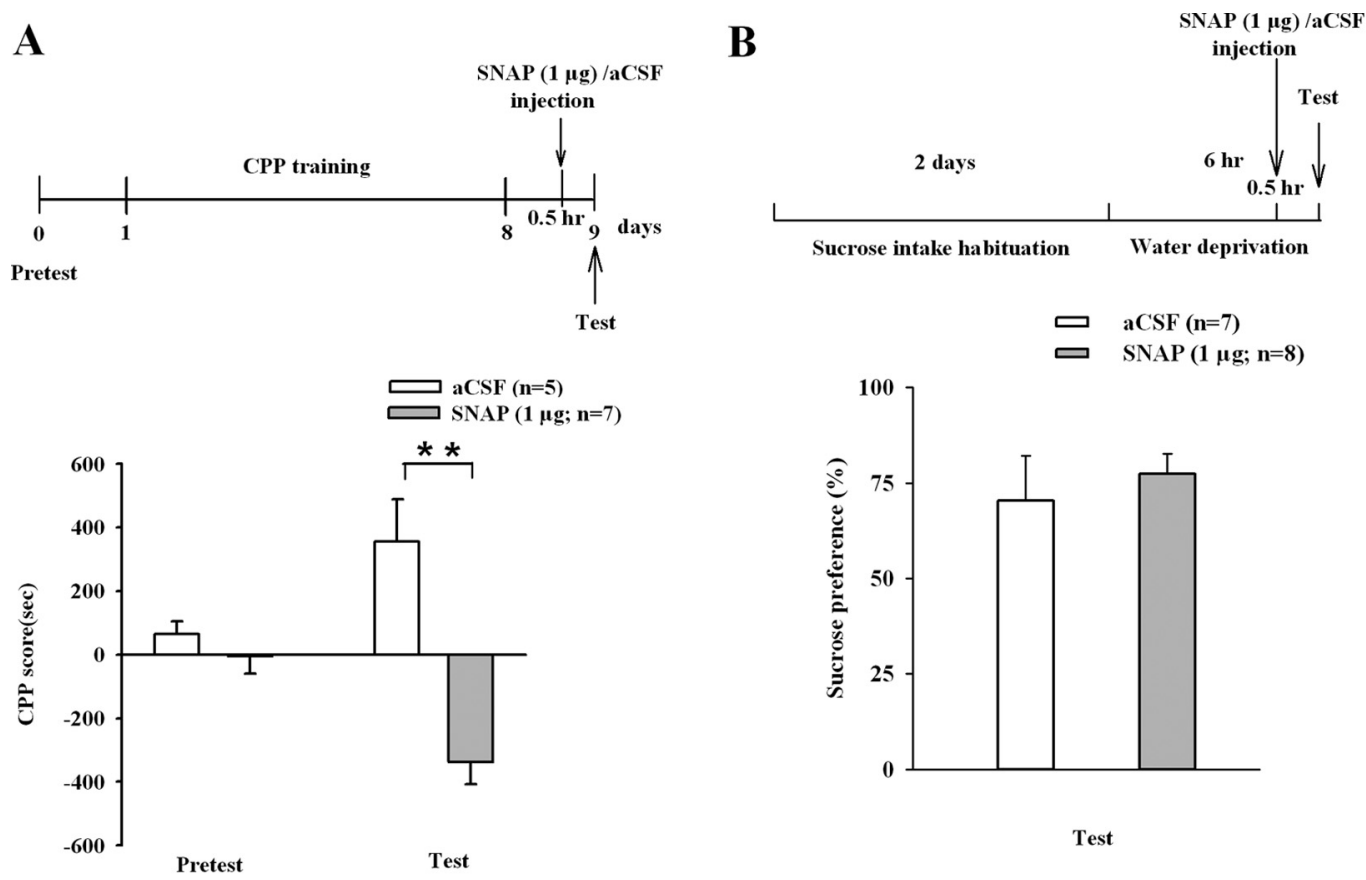

C

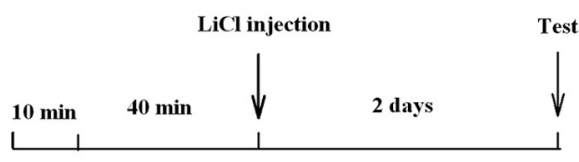

Saccharin

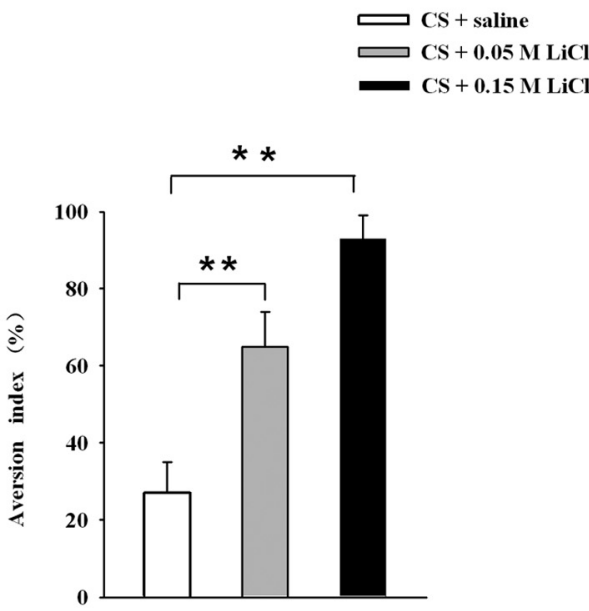

Test
D
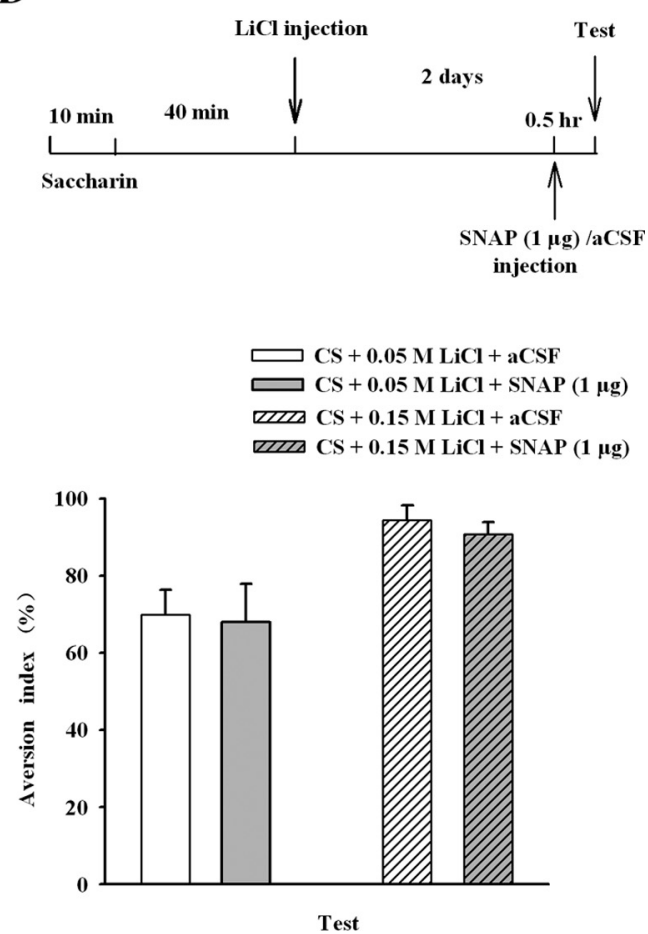

Figure 7. N0 treatment prevents the expression of CPP but not SPT or CPA. A, Bilateral accumbal injections of SNAP $(1 \mu \mathrm{g}) 30$ min before test attenuated the expression of CPP in cocaine-treated rats $\left(n=5-7\right.$ rats per group, ${ }^{* *} p<0.01$, different from aCSF). B, Bilateral accumbal injections of SNAP (1 $\left.\mu \mathrm{g}\right)$ did not affect sucrose preference. C, Al was measured during CTA test in the control (CS + saline), weak CTA (CS $+0.05 \mathrm{M} \mathrm{LiCl)} \mathrm{and} \mathrm{strong} \mathrm{CTA} \mathrm{(CS}+0.15 \mathrm{M} \mathrm{LiCl)} \mathrm{groups.} \mathrm{Rats} \mathrm{in} \mathrm{the} \mathrm{strong} \mathrm{CTA} \mathrm{group} \mathrm{showed} \mathrm{a} \mathrm{significantly} \mathrm{higher} \mathrm{Al} \mathrm{after} \mathrm{conditioning} \mathrm{compared} \mathrm{with} \mathrm{animals} \mathrm{in} \mathrm{the}$ other two groups $\left(n=6-8\right.$ rats per group; one-way ANOVA, $\left.{ }^{* *} p<0.01\right)$. D, Al was measured during (TA test in the weak CTA with aCSF (CS + 0.05 m LiCl + aCSF), weak CTA with SNAP (CS + $0.05 \mathrm{~m} \mathrm{LiCl}+\mathrm{SNAP})$, strong CTA with aCSF (CS + $0.15 \mathrm{~m} \mathrm{LiCl}+\mathrm{aCSF})$, and strong CTA with SNAP (CS + $0.15 \mathrm{~m} \mathrm{LiCl}+$ SNAP) groups. Bilateral accumbal injections of SNAP (1 $\mu \mathrm{g})$ did not affect weak CTA or strong CTA ( $n=6-8$ rats per group). All data are mean \pm SEM.

Trafficking of GluR2-containing AMPARs in the nucleus accumbens and the expression of behavioral sensitization to cocaine

On the other hand, we ascribed this effect to a suppressive action of NSF-GluR2 interactions on the increased surface expression of GluR2-containing AMPARs. We used a peptide, TAT-pep-
R845A, that facilitates the internalization of GluR2-containing AMPARs into cells. Administration of TAT-pep-R845A directly into the NAc increased the locomotor activity to cocaine, suggesting that this behavior was at least partially dependent on the removal of GluR2-containing AMPARs from synapses in the NAc. Another peptide, Pep2-EVKI, which mimics C terminus 


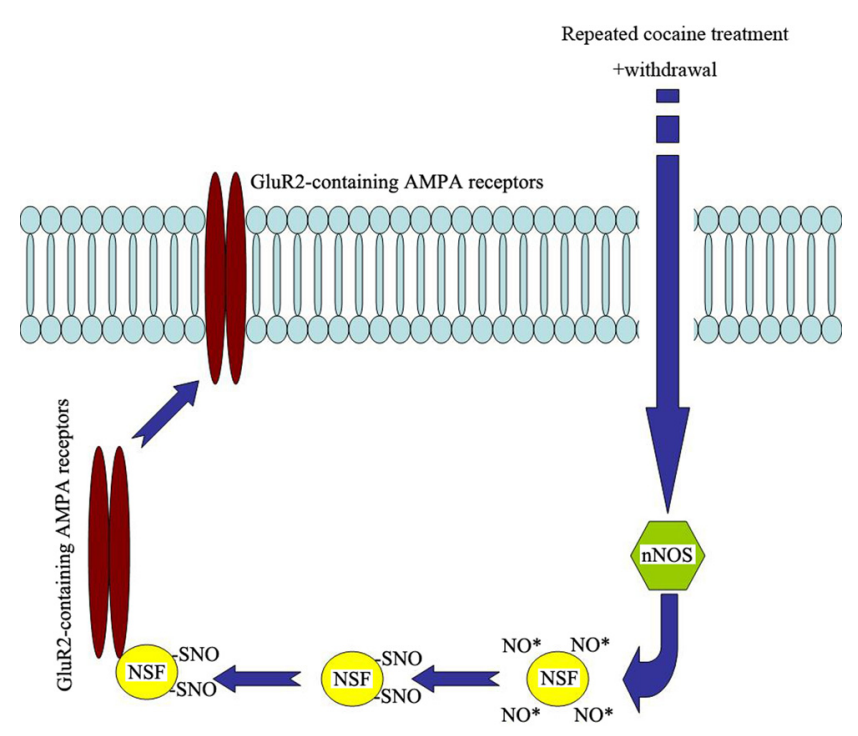

Figure 8. Proposed model of signaling molecules involved in N0-mediated regulation of GluR2-containing AMPAR trafficking. Withdrawal from repeated cocaine exposure activates nNOS, causing NO formation. NO generated in close proximity to NSF nitrosylates NSF. S-nitrosylation of NSF increases its binding to the GluR2 subunit and promotes the surface expression of GluR2-containing AMPARs.

residues of GluR2, disrupts the interactions between GluR2 and PICK1. Our results showed that administration of Pep2-EVKI directly into the NAc attenuated the expression of behavioral sensitization to cocaine, which provided further evidence that impairment of the internalization of GluR2-containing AMPARs in the NAc disrupted the cocaine sensitization. Similarly, intraaccumbal administration of a peptide (Tat-GluR23Y) that specifically blocks the endocytosis of postsynaptic GluR2-containing AMPARs attenuates the expression of behavioral sensitization to amphetamine (Brebner et al., 2005). Prevention of the removal of GluR2-containing AMPARs from synapses in the NAc shell attenuates the reinstatement of cocaine seeking (Famous et al., 2008). A recent study indicates that disrupted the trafficking of GluA2-containing AMPARs by inhibition of PICK1 in the shell attenuates cocaine seeking (Schmidt et al., 2013). Thus, promoting GluR2-containing AMPARs transport to accumbens cell surface or disrupting GluR2-containing AMPARs endocytosis could attenuate cocaine-induced behavior sensitization. It seems very interesting that surface AMPARs upregulation is no longer detected on WD41 whereas locomotor sensitization was still detected on WD41-WD44 after noncontingent cocaine injections (McCutcheon et al., 2011). One explanation, proposed previously, is that although increased surface expression of AMPARs in the NAc represents a mechanism of tolerance to locomotor sensitization during earlier withdrawal times, this compensatory mechanism may break down after prolonged withdrawal from noncontingent cocaine exposure.

It has been shown that HSV-gluR2-mediated overexpression of GluR2 in the NAc markedly enhances the place conditioning to cocaine (Kelz et al., 1999). Transient increases in the expression of GluR2 decreases intracranial self-stimulation thresholds, an effect similar to that caused by rewarding treatments (Todtenkopf et al., 2006). However, the mechanisms that enhanced rewarding effect in these studies by overexpression of GluR2 remain unclear. The cellular location of new AMPARs subunit overexpressed by viral cannot be assumed to be synaptic (Shi et al., 1999). Furthermore, overexpression of GluR2 could influence the availability of AMPAR-interacting proteins that regulate endogenous AMPARs trafficking or alter the normal profile of AMPAR subunit composition. Thus, overexpression of GluR2 cannot rule out possible confounding effects on synaptic functions. Considering these observations, our results suggest that increase in synaptic GluR2-containing AMPARs may produce a beneficial effect on addiction-related behaviors.

\section{NO signal and cocaine behavioral effects}

It is known that NO transmission modulates neuronal excitability and synaptic plasticity (Nowicky and Bindman, 1993; Sardo et al., 2003; Fejgin et al., 2008). As a secondary messenger, NO produces wide biological effects via activating GC-cGMP-PKG signaling (Arnold et al., 1977; Miki et al., 1977; Karatinos et al., 1995; Mustafa et al., 2009; Garthwaite, 2010). The evidence demonstrates that acute and repeated cocaine administration upregulates NO levels in the medial prefrontal cortex and the dorsal striatum, respectively (Sammut and West, 2008; Lee et al., 2010). It has been suggested that NO may play a major role in initiating and maintaining the behavioral effects of psychostimulant drugs (Karatinos et al., 1995; Kim and Park, 1995; Bhargava and Kumar, 1997; Nugent et al., 2007) and the behavioral sensitization caused by repeated cocaine exposure is prevented by pretreatment of previously drug-naive animals with the nNOS inhibitor 7-nitroindazole or the pan NOS inhibitor $N$ - $\omega$-nitro-L-arginine methyl ester (Itzhak, 1996; Haracz et al., 1997; Byrnes et al., 2000). Recent studies have revealed that GC-cGMP-PKG signaling regulates the release of dopamine, the trafficking of GluR1 and locomotor activity after repeated cocaine administration (Lee et al., 2013; Seo et al., 2013). Thus, NO-GC-cGMP-PKG signaling contributes to behavioral changes in response to repeated exposure to cocaine. It should be noted that NO can initiate other effects via reacting directly with proteins sulfhydryl groups of cysteine, a phenomenon called protein S-nitrosylation (Stamler et al., 2001; Garthwaite, 2008). Recent study reports that $15 \mathrm{mg} / \mathrm{kg}$ doses of cocaine triggers the formation of nitrosylated GAPDH/Siah1 complex leading to increased expression of CREB genes (Xu et al., 2013), and cocaine-induced activation of CREB signaling is considered to be an important compensatory response that decreases the motivational properties of the drug (Carlezon et al., 1998; McClung and Nestler, 2003). In this study, we observed that withdrawal from repeated cocaine increased the S-nitrosylation of NSF, which may promote its binding to the GluR2 subunit of AMPAR and prevent behavioral adaptations to stimulant drugs. However, there may be other mechanisms by which NO may regulate AMPAR trafficking. For instance, Selvakumar et al. (2013) found that S-nitrosylation of the AMPAR auxiliary subunit stargazin contributed to the increased surface expression of AMPAR in the NAc shell after withdrawal from a sensitizing regimen of cocaine. Activation of cGMP, a downstream effector of NO, increased surface expression of AMPARs in cultured neurons (Serulle et al., 2007). Moreover, an unexpected basis for the reverse of cocaine-induced conditioned place preference by NO was unresolved in the present study. Thus, the precise mechanism for the effect of $\mathrm{NO}$ on addiction requires further investigation.

\section{Conclusions}

The present study indicated that after withdrawal from noncontingent cocaine injections increased NSF-GluR2 interactions in the NAc. Disrupted or further increased accumbal NSF-GluR2 interactions enhanced or attenuated the responses of rat to cocaine by inhibiting or promoting the surface expression of 
GluR2-containing AMPARs. Together, these results suggest that the expression of behavioral sensitization negative regulated by NSF-GluR2 interactions in the NAc.

\section{References}

Arnold WP, Mittal CK, Katsuki S, Murad F (1977) Nitric oxide activates guanylate cyclase and increases guanosine $3^{\prime}: 5^{\prime}$-cyclic monophosphate levels in various tissue preparations. Proc Natl Acad Sci U S A 74:32033207. CrossRef Medline

Bachtell RK, Self DW (2008) Renewed cocaine exposure produces transient alterations in nucleus accumbens AMPA receptor-mediated behavior. J Neurosci 28:12808-12814. CrossRef Medline

Baratta M, Saleri R, Mainardi GL, Valle D, Giustina A, Tamanini C (2002) Leptin regulates $\mathrm{GH}$ gene expression and secretion and nitric oxide production in pig pituitary cells. Endocrinology 143:551-557. CrossRef Medline

Bhargava HN, Kumar S (1997) Sensitization to the locomotor stimulant activity of cocaine is associated with increases in nitric oxide synthase activity in brain regions and spinal cord of mice. Pharmacology 55:292298. CrossRef Medline

Boudreau AC, Wolf ME (2005) Behavioral sensitization to cocaine is associated with increased AMPA receptor surface expression in the nucleus accumbens. J Neurosci 25:9144-9151. CrossRef Medline

Boudreau AC, Reimers JM, Milovanovic M, Wolf ME (2007) Cell surface AMPA receptors in the rat nucleus accumbens increase during cocaine withdrawal but internalize after cocaine challenge in association with altered activation of mitogen-activated protein kinases. J Neurosci 27: 10621-10635. CrossRef Medline

Boudreau AC, Ferrario CR, Glucksman MJ, Wolf ME (2009) Signaling pathway adaptations and novel protein kinase A substrates related to behavioral sensitization to cocaine. J Neurochem 110:363-377. CrossRef Medline

Brebner K, Wong TP, Liu L, Liu Y, Campsall P, Gray S, Phelps L, Phillips AG, Wang YT (2005) Nucleus accumbens long-term depression and the expression of behavioral sensitization. Science 310:1340-1343. CrossRef Medline

Byrnes JJ, Pantke MM, Onton JA, Hammer RP Jr (2000) Inhibition of nitric oxide synthase in the ventral tegmental area attenuates cocaine sensitization in rats. Prog Neuropsychopharmacol Biol Psychiatry 24:261-273. CrossRef Medline

Carlezon WA Jr, Thome J, Olson VG, Lane-Ladd SB, Brodkin ES, Hiroi N, Duman RS, Neve RL, Nestler EJ (1998) Regulation of cocaine reward by CREB. Science 282:2272-2275. CrossRef Medline

Conrad KL, Tseng KY, Uejima JL, Reimers JM, Heng LJ, Shaham Y, Marinelli M, Wolf ME (2008) Formation of accumbens GluR2-lacking AMPA receptors mediates incubation of cocaine craving. Nature 454:118-121. CrossRef Medline

Famous KR, Kumaresan V, Sadri-Vakili G, Schmidt HD, Mierke DF, Cha JH, Pierce RC (2008) Phosphorylation-dependent trafficking of GluR2containing AMPA receptors in the nucleus accumbens plays a critical role in the reinstatement of cocaine seeking. J Neurosci 28:11061-11070. CrossRef Medline

Fejgin K, Pålsson E, Wass C, Svensson L, Klamer D (2008) Nitric oxide signaling in the medial prefrontal cortex is involved in the biochemical and behavioral effects of phencyclidine. Neuropsychopharmacology 33: 1874-1883. CrossRef Medline

Ferrario CR, Li X, Wang X, Reimers JM, Uejima JL, Wolf ME (2010) The role of glutamate receptor redistribution in locomotor sensitization to cocaine. Neuropsychopharmacology 35:818-833. CrossRef Medline

Ferrario CR, Loweth JA, Milovanovic M, Ford KA, Galiñanes GL, Heng LJ, Tseng KY, Wolf ME (2011) Alterations in AMPA receptor subunits and TARPs in the rat nucleus accumbens related to the formation of $\mathrm{Ca}(2)(+)$-permeable AMPA receptors during the incubation of cocaine craving. Neuropharmacology 61:1141-1151. CrossRef Medline

Garthwaite J (2008) Concepts of neural nitric oxide-mediated transmission. Eur J Neurosci 27:2783-2802. CrossRef Medline

Garthwaite J (2010) New insight into the functioning of nitric oxidereceptive guanylyl cyclase: physiological and pharmacological implications. Mol Cell Biochem 334:221-232. CrossRef Medline

Hanley JG, Khatri L, Hanson PI, Ziff EB (2002) NSF ATPase and alpha-/ beta-SNAPs disassemble the AMPA receptor-PICK1 complex. Neuron 34:53-67. CrossRef Medline
Haracz JL, MacDonall JS, Sircar R (1997) Effects of nitric oxide synthase inhibitors on cocaine sensitization. Brain Res 746:183-189. CrossRef Medline

Huang Y, Man HY, Sekine-Aizawa Y, Han Y, Juluri K, Luo H, Cheah J, Lowenstein C, Huganir RL, Snyder SH (2005) S-nitrosylation of $\mathrm{N}$-ethylmaleimide sensitive factor mediates surface expression of AMPA receptors. Neuron 46:533-540. CrossRef Medline

Itzhak Y (1996) Attenuation of cocaine kindling by 7-nitroindazole, an inhibitor of brain nitric oxide synthase. Neuropharmacology 35:1065-1073. CrossRef Medline

Jaffrey SR, Erdjument-Bromage H, Ferris CD, Tempst P, Snyder SH (2001) Protein S-nitrosylation: a physiological signal for neuronal nitric oxide. Nat Cell Biol 3:193-197. CrossRef

Jaffrey SR, Fang M, Snyder SH (2002) Nitrosopeptide mapping: a novel methodology reveals S-nitrosylation of dexras1 on a single cysteine residue. Chem Biol 9:1329-1335. CrossRef Medline

Joels G, Lamprecht R (2010) Interaction between N-ethylmaleimidesensitive factor and GluR2 is essential for fear memory formation in lateral amygdala. J Neurosci 30:15981-15986. CrossRef

Karatinos J, Rosse RB, Deutsch SI (1995) The nitric oxide pathway: potential implications for treatment of neuropsychiatric disorders. Clin Neuropharmacol 18:482-499. CrossRef Medline

Kelley AE (2004) Ventral striatal control of appetitive motivation: role in ingestive behavior and reward-related learning. Neurosci Biobehav Rev 27:765-776. CrossRef Medline

Kelz MB, Chen J, Carlezon WA Jr, Whisler K, Gilden L, Beckmann AM, Steffen C, Zhang YJ, Marotti L, Self DW, Tkatch T, Baranauskas G, Surmeier DJ, Neve RL, Duman RS, Picciotto MR, Nestler EJ (1999) Expression of the transcription factor deltaFosB in the brain controls sensitivity to cocaine. Nature 401:272-276. CrossRef Medline

Kim HS, Park WK (1995) Nitric oxide mediation of cocaine-induced dopaminergic behaviors: ambulation-accelerating activity, reverse tolerance and conditioned place preference in mice. J Pharmacol Exp Ther 275: 551-557. Medline

Kourrich S, Klug JR, Mayford M, Thomas MJ (2012) AMPAR-independent effect of striatal alphaCaMKII promotes the sensitization of cocaine reward. J Neurosci 32:6578-6586. CrossRef Medline

Koya E, Cruz FC, Ator R, Golden SA, Hoffman AF, Lupica CR, Hope BT (2012) Silent synapses in selectively activated nucleus accumbens neurons following cocaine sensitization. Nat Neurosci 15:1556-1562. CrossRef Medline

Lee DK, Koh WC, Shim YB, Shim I, Choe ES (2010) Repeated cocaine administration increases nitric oxide efflux in the rat dorsal striatum. Psychopharmacology 208:245-256. CrossRef Medline

Lee DK, Oh JH, Shim YB, Choe ES (2013) Protein kinase G regulates dopamine release, DeltaFosB expression, and locomotor activity after repeated cocaine administration: involvement of dopamine D2 receptors. Neurochem Res 38:1424-1433. CrossRef Medline

Lee SH, Liu L, Wang YT, Sheng M (2002) Clathrin adaptor AP2 and NSF interact with overlapping sites of GluR2 and play distinct roles in AMPA receptor trafficking and hippocampal LTD. Neuron 36:661-674. CrossRef Medline

Lüthi A, Chittajallu R, Duprat F, Palmer MJ, Benke TA, Kidd FL, Henley JM, Isaac JT, Collingridge GL (1999) Hippocampal LTD expression involves a pool of AMPARs regulated by the NSF-GluR2 interaction. Neuron 24: 389-399. CrossRef Medline

Ma L, Wang DD, Zhang TY, Yu H, Wang Y, Huang SH, Lee FS, Chen ZY (2011) Region-specific involvement of BDNF secretion and synthesis in conditioned taste aversion memory formation. J Neurosci 31:2079-2090. CrossRef Medline

Mameli M, Halbout B, Creton C, Engblom D, Parkitna JR, Spanagel R, Lüscher C (2009) Cocaine-evoked synaptic plasticity: persistence in the VTA triggers adaptations in the NAc. Nat Neurosci 12:1036-1041. CrossRef Medline

Mao LM, Wang W, Chu XP, Zhang GC, Liu XY, Yang YJ, Haines M, Papasian CJ, Fibuch EE, Buch S, Chen JG, Wang JQ (2009) Stability of surface NMDA receptors controls synaptic and behavioral adaptations to amphetamine. Nat Neurosci 12:602-610. CrossRef Medline

McClung CA, Nestler EJ (2003) Regulation of gene expression and cocaine reward by CREB and DeltaFosB. Nat Neurosci 6:1208-1215. CrossRef Medline

McCutcheon JE, Wang X, Tseng KY, Wolf ME, Marinelli M (2011) 
Calcium-permeable AMPA receptors are present in nucleus accumbens synapses after prolonged withdrawal from cocaine self-administration but not experimenter-administered cocaine. J Neurosci 31:5737-5743. CrossRef Medline

Miki N, Kawabe Y, Kuriyama K (1977) Activation of cerebral guanylate cyclase by nitric oxide. Biochem Biophys Res Commun75:851-856. CrossRef Medline

Mustafa AK, Gadalla MM, Snyder SH (2009) Signaling by gasotransmitters. Sci Signal 2:re2. CrossRef Medline

Nishimune A, Isaac JT, Molnar E, Noel J, Nash SR, Tagaya M, Collingridge GL, Nakanishi S, Henley JM (1998) NSF binding to GluR2 regulates synaptic transmission. Neuron 21:87-97. CrossRef Medline

Nowicky AV, Bindman LJ (1993) The nitric oxide synthase inhibitor, $\mathrm{N}$-monomethyl-L-arginine blocks induction of a long-term potentiationlike phenomenon in rat medial frontal cortical neurons in vitro. J Neurophysiol 70:1255-1259. Medline

Nugent FS, Penick EC, Kauer JA (2007) Opioids block long-term potentiation of inhibitory synapses. Nature 446:1086-1090. CrossRef Medline

Robinson TE, Berridge KC (1993) The neural basis of drug craving: an incentive-sensitization theory of addiction. Brain Res Brain Res Rev 18: 247-291. CrossRef Medline

Sammut S, West AR (2008) Acute cocaine administration increases NO efflux in the rat prefrontal cortex via a neuronal NOS-dependent mechanism. Synapse 62:710-713. CrossRef Medline

Sardo P, Ferraro G, Di Giovanni G, La Grutta V (2003) Nitric oxide-induced inhibition on striatal cells and excitation on globus pallidus neurons: a microiontophoretic study in the rat. Neurosci Letters 343:101-104. CrossRef Medline

Schmidt HD, Pierce RC (2010) Cocaine-induced neuroadaptations in glutamate transmission: potential therapeutic targets for craving and addiction. Ann N Y Acad Sci 1187:35-75. CrossRef Medline

Schmidt HD, Schassburger RL, Guercio LA, Pierce RC (2013) Stimulation of mGluR5 in the accumbens shell promotes cocaine seeking by activating PKC gamma. J Neurosci 33:14160-14169. CrossRef Medline

Schumann J, Yaka R (2009) Prolonged withdrawal from repeated noncontingent cocaine exposure increases NMDA receptor expression and ERK activity in the nucleus accumbens. J Neurosci 29:6955-6963. CrossRef Medline

Selvakumar B, Campbell PW, Milovanovic M, Park DJ, West AR, Snyder SH,
Wolf ME (2013) AMPA receptor upregulation in the nucleus accumbens shell of cocaine-sensitized rats depends upon S-nitrosylation of stargazin. Neuropharmacology. Sep 10.

Seo SY, Oh JH, Choe ES (2013) Protein kinase G increases AMPA receptor GluR1 phosphorylation at serine 845 after repeated cocaine administration in the rat nucleus accumbens. Neurosci Lett 544:147-151. CrossRef Medline

Serulle Y, Zhang S, Ninan I, Puzzo D, McCarthy M, Khatri L, Arancio O, Ziff EB (2007) A GluR1-cGKII interaction regulates AMPA receptor trafficking. Neuron 56:670-688. CrossRef Medline

Shi SH, Hayashi Y, Petralia RS, Zaman SH, Wenthold RJ, Svoboda K, Malinow R (1999) Rapid spine delivery and redistribution of AMPA receptors after synaptic NMDA receptor activation. Science 284:1811-1816. CrossRef Medline

Shi S, Hayashi Y, Esteban JA, Malinow R (2001) Subunit-specific rules governing AMPA receptor trafficking to synapses in hippocampal pyramidal neurons. Cell 105:331-343. CrossRef Medline

Song I, Kamboj S, Xia J, Dong H, Liao D, Huganir RL (1998) Interaction of the $\mathrm{N}$-ethylmaleimide-sensitive factor with AMPA receptors. Neuron 21: 393-400. CrossRef Medline

Stamler JS, Lamas S, Fang FC (2001) Nitrosylation. the prototypic redoxbased signaling mechanism. Cell 106:675-683. CrossRef Medline

Todtenkopf MS, Parsegian A, Naydenov A, Neve RL, Konradi C, Carlezon WA Jr (2006) Brain reward regulated by AMPA receptor subunits in nucleus accumbens shell. J Neurosci 26:11665-11669. CrossRef Medline

Wolf ME (1998) The role of excitatory amino acids in behavioral sensitization to psychomotor stimulants. Prog Neurobiol 54:679-720. CrossRef Medline

Wolf ME, Ferrario CR (2010) AMPA receptor plasticity in the nucleus accumbens after repeated exposure to cocaine. Neurosci Biobehav Rev 35 185-211. CrossRef Medline

Wolf ME, Tseng KY (2012) Calcium-permeable AMPA receptors in the VTA and nucleus accumbens after cocaine exposure: when, how, and why? Front Mol Neuroscience 5:72. CrossRef Medline

Xu R, Serritella AV, Sen T, Farook JM, Sedlak TW, Baraban J, Snyder SH, Sen N (2013) Behavioral effects of cocaine mediated by nitric oxideGAPDH transcriptional signaling. Neuron 78:623-630. CrossRef Medline 